\title{
Memory in Posttraumatic Stress Disorder: Properties of Voluntary and Involuntary, Traumatic and Nontraumatic Autobiographical Memories in People With and Without Posttraumatic Stress Disorder Symptoms
}

\author{
David C. Rubin \\ Duke University
}

\author{
Adriel Boals \\ University of North Texas
}

Dorthe Berntsen
University of Aarhus

\begin{abstract}
One hundred fifteen undergraduates rated 15 word-cued memories and their 3 most negatively stressful, 3 most positive, and 7 most important events and completed tests of personality and depression. Eighty-nine also recorded involuntary memories online for 1 week. In the first 3-way comparisons needed to test existing theories, comparisons were made of memories of stressful events versus control events and involuntary versus voluntary memories in people high versus low in posttraumatic stress disorder (PTSD) symptom severity. For all participants, stressful memories had more emotional intensity, more frequent voluntary and involuntary retrieval, but not more fragmentation. For all memories, participants with greater PTSD symptom severity showed the same differences. Involuntary memories had more emotional intensity and less centrality to the life story than voluntary memories. Meeting the diagnostic criteria for traumatic events had no effect, but the emotional responses to events did. In 533 undergraduates, correlations among measures were replicated and the Negative Intensity factor of the Affect Intensity Measure correlated with PTSD symptom severity. No special trauma mechanisms were needed to account for the results, which are summarized by the autobiographical memory theory of PTSD.
\end{abstract}

Keywords: autobiographical memory, PTSD, life story, intrusive memories, fragmentation

The role of memory for traumatic events has been long debated in psychology (e.g., Conway, 1997; Kihlstrom, 1997, 2006; Loftus, 1993; McNally, 2003a, 2003b). Here we examine autobiographical memory in relation to posttraumatic stress disorder (PTSD) - a disorder that may follow exposure to traumatic events. We present detailed findings from a comprehensive series of studies specifically designed to address some of the key controversies about the role of the traumatic memory in PTSD. We contrast two views. We label one view the special mechanisms view, because it explains PTSD in terms of hypothesized memory mechanisms that are special to traumatic events or PTSD, and the other the basic mechanisms view, because it argues that PTSD can be accounted for by basic psychological mechanisms related to memory, emotion, and personality. Such a distinction has frequently been used in the literature on trauma and memory (e.g.,

David C. Rubin, Department of Psychology and Neuroscience, Duke University; Adriel Boals, Department of Psychology, University of North Texas; Dorthe Berntsen, Department of Psychology, University of Aarhus, Aarhus, Denmark.

This work was supported by National Institute of Mental Health Grant R01 MH066079 and by a grant from the Danish Research Council for Culture and Communication. We thank John Kihlstrom for comments and Ilene Siegler for her help with the analysis of the NEO data.

Correspondence concerning this article should be addressed to David C. Rubin, Department of Psychology and Neuroscience, Box 90086, Duke University, Durham, NC 27708-0086. E-mail: david.rubin@duke.edu
Brewin, 2007; Kihlstrom, 2006; Nadel \& Jacobs, 1998) and is useful here as well. In the introduction, we review the relevant literature and extract predictions that differentiate the two views in the present context. In the General Discussion, we propose a theory of PTSD consistent with the basic mechanisms view and the results obtained here.

\section{PTSD and Cognitive Theories of PTSD}

\section{The Definition of PTSD}

To have PTSD, one must have six key diagnostic criteria (labeled A through F in the Diagnostic and Statistical Manual of Mental Disorders, 4th ed., text rev. [DSM-IV-TR]; American Psychiatric Association, 2000, pp. 467-468). Three criteria follow almost by definition from the three components of the name post, traumatic stress, and disorder: There must be (A) a severe trauma that $(\mathrm{F})$ causes clinically significant distress or impairment $(\mathrm{E})$ for more than a month. The trauma is defined as having both an A1 component, "the person experienced, witnessed, or was confronted with an event or events that involved actual or threatened death or serious injury, or a threat to the physical integrity of self or others," and an A2 component, "the person's response involved intense fear, helplessness, or horror." In addition, focusing on the symptoms under the $\mathrm{B}, \mathrm{C}$, and $\mathrm{D}$ headings that are most relevant here, (B) "the traumatic event is persistently reexperienced," including (B1) "recurrent and intrusive distressing recollections," (B3) "acting or feeling as if the traumatic event were recurring (includes a 
sense of reliving the experience, ...)," and (B5) "physiological reactivity on exposure to internal or external cues." There needs to be (C) "persistent avoidance of stimuli associated with the trauma and numbing of general responsiveness" that can include an (C3) "inability to recall an important aspect of the trauma." Finally, there needs to be (D) "persistent symptoms of increased arousal."

For our purposes, two points about the formal diagnosis should be stressed. First, PTSD is caused by an event that occurs at least a month before a diagnosis can be made. Thus, the memory of that event maintains the disorder, either as a conscious autobiographical memory (Rubin, Berntsen, \& Bohni, in press) or in forms not available to conscious recall. Second, according to the diagnosis, PTSD is defined in large part by changes that occur specifically in autobiographical memory; patients may experience fragmented memories and intrusive involuntary memories related to the trauma. Memory function in general need not be affected.

\section{The Two Contrasting Views}

In the following, we describe the key differences between the special versus basic mechanisms views. Both views emphasize the importance of memory in PTSD but with very different implications. One important and overarching difference between these views has to do with different research aims. The special mechanisms view derives from clinical research on PTSD for which, according to Dalgleish (2004),

a theory of PTSD should offer an account of the symptoms of the disorder and their treatment, should have prospective utility in terms of being a tool for thinking about how treatments might be developed and/or why existing treatments might fail for some individuals, and ideally, should be reducible to a digestible form that can be discussed with patients to provide them with a rationale for the treatment that is being carried out. (p. 253)

The basic mechanisms view, on the other hand, derives from naturalistic and experimental research on memory, with the aim of providing a broad understanding of memory in diverse contexts, including, but not limited to, traumatic events. As described by Dalgleish (2004), compared with the clinical PTSD researcher,

a basic science/pure theorist ... has an altogether different set of expectations of a theory than the clinician/clinical researcher .... Pure theorists are more motivated to broaden theoretical horizons from disorder-specific, microtheoretical approaches (such as those that focus only on PTSD) to ... models that embrace various psychopathological and nonpsychopathological presentations. (p. 253)

Because of the different research aims and practices associated with the two views, they have not been evaluated against one another in a comprehensive set of studies specifically designed to address predictions that would differentiate them.

A second important overarching difference is the nature of the memory that results from an extremely stressful or traumatic event. For both the basic and special mechanisms views, there should be an increase in emotional arousal or intensity and, for most such events, an increase in schema violations, compared with reactions to mundane events. For the basic mechanisms view, this should lead to enhanced encoding and more available voluntary and involuntary memory of the event. For the special mechanisms view, this should lead to impoverished encoding of the voluntary memory but enhanced availability of the involuntary memory (Hall \& Berntsen, 2008). Put in this very simple form, which we expand on shortly, the difference is not only between clinical theories of specific disorders and general theories of behavior but also between a highly available memory that is as coherent as the event allows and a fragmented memory that cannot easily be recalled voluntarily as a coherent narrative. Viewed this way, some cognitive theorists support the special mechanisms view (e.g., Freyd, 1994; Metcalfe, \& Jacobs, 1998; Nadel \& Jacobs, 1998) just as some clinical and experimental scientists explicitly oppose it (e.g., Geraerts et al., 2007; Kihlstrom, 2006; McNally, 2007; Peace, Porter, \& ten Brinke, 2008; Porter \& Birt, 2001; Zoellner \& Bittenger, 2004). In the following, we describe the key assumptions of each view as applied to PTSD and then focus on their differential predictions.

\section{The Special Mechanisms View}

This view refers to a cluster of PTSD theories that differ on details but share the following three basic theoretical assumptions. First, a traumatic event is assumed to instigate mechanisms, such as peritraumatic dissociation, that have seriously disruptive effects on the encoding and integration of the traumatic event in memory (e.g., Van der Kolk \& Fisler, 1995). Second, as a consequence, voluntary (controlled and goal-directed) access to the trauma memory is impaired, whereas involuntary (uncontrolled and unintended) access is enhanced. Thus, the PTSD patient is likely to be flooded by involuntary intrusive memories of the trauma while having difficulties recalling the traumatic event in a controlled and goal-directed fashion. Third, although both types of recall lead to the activation of a conscious, explicit memory, voluntary versus involuntary remembering are argued to reflect the operations of two distinct memory systems or fundamentally different processes. Involuntary remembering is assumed to be particularly prevalent in relation to accessing and reliving traumatic events. Finally, these effects may characterize all traumatic memories, but they are more pronounced for traumatic memories in individuals with versus without PTSD. This view is found in many theories and is summarized very clearly by Ehlers and Clark (2000):

The nature of trauma memory and its relationship to unwanted recollections is another puzzle of persistent PTSD. On the one hand patients often have difficulty in intentionally retrieving a complete memory of the traumatic event. Their intentional recall is fragmented and poorly organized, details may be missing and they have difficulties recalling the exact temporal order of the events .... On the other hand, patients report a high frequency of involuntarily triggered intrusive memories involving reexperiencing aspects of the event in a very vivid and emotional way. Models of PTSD need to explain this apparent discrepancy between difficulties in intentional recall and easily triggered reexperiencing aspects of the event. (p. 324)

An early representative of this view is Horowitz (1986). Horowitz's basic idea is that because the integration of the memory of the trauma fails, continued attempts are made at integration, thereby keeping the memory active. However, because of the extremely negative nature of the trauma, processes are invoked to keep these integration attempts from consciousness. The conflicts that arise from these processes produce many of the symptoms of PTSD. Janoff-Bulman's (1988) theory is similar to Horowitz's in that it 
conceives of memory organization in terms of general schema and sees the lack of integration of the trauma memory into existing schemata as central. Compared with Horowitz's idea, it is more existential and abstract in that details of the trauma are not as important as its challenge to basic beliefs about the world, notably basic assumptions about the benevolence of the world, meaningfulness of life, and self-worthiness.

Brewin, Dalgleish, and Joseph's (1996) dual representation theory can be seen as more complex than the two theories just discussed because it accounts for the nonintegrated trauma memory by using two separate memory systems (Brewin \& Holmes, 2003; Dalgleish, 2004). The situationally accessible memory system is limited to material that can be accessed only involuntarily through situational cues. It is also limited to material that was not fully consciously processed at the time of encoding, for which reason this memory system dominates after traumatic events and repeatedly brings to mind sensory and emotional fragments of the trauma. The counterpart to the situationally accessible memory system is the verbally accessible memory system. It includes material that was consciously processed during the traumatic event and that therefore can be accessed through voluntary recall and described verbally. The situationally accessible memory versus verbally accessible memory division cuts across divisions that are used to account for data in cognitive psychology in complex and nonstandard ways (e.g., coding in sensory vs. language systems, implicit vs. explicit memory, voluntary vs. involuntary memory). Similarly, Ehlers and Clark (2000) used two mechanisms to account for the assumed properties of PTSD. One component is appraisal of the current threat; the other is the lack of integration of the trauma memory with the rest of the person's autobiographical memories. The latter leads to hampered voluntary memory for the trauma together with frequent involuntary trauma memory consisting of a high level of sensory (especially visual) imagery and emotional reliving.

\section{The Basic Mechanisms View}

This view applies research on emotion, autobiographical memory, and personality in general to account for symptoms of PTSD without using special mechanisms for trauma or PTSD (e.g., Berntsen, in press; Berntsen \& Rubin, 2006c, 2007, 2008; Rubin, 2006; Rubin et al., in press; Rubin \& Siegler, 2004). Thus, we use only empirically based, well-tested theories and observations from general psychology to build our model. We assume no differences between processes or systems unless they have been clearly demonstrated. First, as in all other behaviors that depend on prior experience (Tversky, \& Kahneman, 1973), the availability ${ }^{1}$ of the traumatic memory determines whether PTSD symptoms will follow, so that PTSD symptoms are assumed to increase with increasing availability of the traumatic memory. This is counter to the first tenet of the special mechanisms view that voluntary access to the trauma memory is impaired. Second, given no strong evidence of differences and considerable evidence for no differences (Berntsen, in press), the basic mechanisms view does not expect availability of a highly stressful event to differ for voluntary versus involuntary recall. Both are expected to show increased availability of the trauma memory with increasing PTSD symptoms.

Third, the two types of recall are not explained in terms of different memory systems. Although the claim of different mem- ory systems is made by the theories that use special mechanisms, no evidence needed to argue for separate memory systems in a cognitive theory of memory (e.g. Tulving, 1983) is present. The differences in behavior are more parsimoniously described in terms of difference in retrieval from the same memory system: an uncontrolled associative spreading activation for the involuntary memories versus a controlled narrative and schema-based search for the voluntary memories. This difference in retrieval leads directly to involuntary memories having greater emotional impact at recall and less life story relevance than voluntary memories (see Berntsen, in press, for details). Fourth, the memory of the event, not the event per se, is central for the development and maintenance of PTSD symptoms. We therefore assume that highly negative events that do not fulfill the diagnostic A1 and A2 event criteria of life danger and fear may be followed by PTSD symptoms to the extent that they are associated with intense negative affect (Rubin et al., in press). The following is a more detailed review of findings motivating the basic mechanisms view.

Numerous neurobiological and behavioral studies on the interplay of affect and memory document that emotional arousal enhances (rather than disrupts) encoding and helps the formation of long-term and highly accessible memories (e.g., McGaugh, 2003; Talarico, LaBar, \& Rubin, 2004). However, not just emotional arousal at the time of encoding determines the availability of the memory. The emotional intensity and valence accompanying an event depend on personality factors, such as neuroticism and temperament, that indicate whether a person will be more likely to focus on negative aspects of life experiences and more likely to react with intense emotions (Rubin et al., in press). Moreover, many of the effects of emotion can be on the continued maintenance of the memory in addition to its initial encoding (Rubin et al., in press). Factors other than emotion can affect availability.

In particular, Berntsen and Rubin (2006c, 2007) introduced the Centrality of Event Scale (CES), which measures the extent to which a stressful or traumatic memory is central to a person's life story and identity and is used as a reference point for the generation of expectations for the future and for the attribution of meaning to other nontraumatic experiences. Thus, the CES is a measure of the general availability of the stressful memory and should correlate with how easily that memory comes to mind involuntarily and is accessed voluntarily. It follows that memories with high CES scores will more frequently occur as intrusive memories and will require greater avoidance of cues to prevent their continued recall. Consistent with this basic mechanisms view, and counter to some special mechanisms theories (e.g., Halligan, Clark, \& Ehlers, 2002; see Brewin, 2007, for a review), the CES is positively correlated with PTSD symptoms (Berntsen \& Rubin, 2006b, 2006c, 2007, 2008). In addition to the effects on overall availability, because the CES measures the centrality to the person's life story, we expect an added effect for any voluntary retrieval of the stressful event that is guided by a narrative search

\footnotetext{
${ }^{1}$ The meaning of availability follows from Asch and Ebenholtz (1962), Thorndike (1932), and Tversky and Kahneman (1973) and refers to the ease with which something comes to mind. It is, unfortunately, in conflict with Tulving and Pearlstone's (1966) distinction between availability and accessibility. See Rubin (1983).
} 
compared with involuntary memory retrieval, which by definition can have no such search.

Following research on involuntary autobiographical memories in everyday life (Berntsen, in press; Hall \& Berntsen, 2008), the basic mechanisms view does not differentiate between involuntary and voluntary recall with regard to the availability of the traumatic event in memory. This claim is counter to the special mechanisms view that the two types of recall yield differential access to traumatic or negative material and that involuntary recall of emotion is especially pronounced for traumatic events. Thus, in the basic mechanism view, enhanced access to the trauma memory in PTSD is found for both involuntary and voluntary recall. Although studies have shown that involuntary recall involves more emotional impact (Berntsen \& Hall, 2004) and reduced access to material with a clear narrative content (Hall \& Berntsen, 2008) as compared with voluntary recall, these effects are not limited to traumatic or emotionally negative material. They are found for involuntary memories in general. These findings reflect the associative and uncontrolled retrieval process of involuntary retrieval, which leaves little warning time to evoke emotion regulation (Gross, 2001) and which is less likely to access memories indexed in terms of narratives than are the controlled, schema-based search strategies that characterize voluntary recall. This allows the basic mechanisms view to explain traumatic flashback (e.g., Frankel, 1994; Hellaway \& Brewin, 2002) with reference to mechanisms that apply to involuntary autobiographical memory in general (Berntsen, in press). Note that the basic mechanisms explanation of differences between involuntary and voluntary processes is not a post hoc special-mechanism explanation made for this study or for PTSD in general. The basis for it is described in detail with supporting empirical studies in earlier publications (e.g., Berntsen, in press; Berntsen \& Rubin, 2008; Hall \& Berntsen, 2008).

\section{Differential Predictions}

Here, we summarize the most important differences between the two views, which allows us to test one view against the other. First, for the special mechanisms view, voluntary access to the traumatic memory is impaired in PTSD whereas involuntary access is enhanced. In contrast, for the basic mechanisms view, both voluntary access and involuntary access to the traumatic memory are enhanced in PTSD. Second, for the special mechanisms view, level of PTSD symptoms is positively correlated with the degree to which the traumatic memory is disintegrated from the autobiographical knowledge base of the person. In contrast, for the basic mechanisms view, the level of PTSD symptoms is positively related to the degree to which the traumatic memory is available for voluntary and involuntary recall and central to the person's life story and identity. Third, for the special mechanisms view, involuntary memories (as compared with voluntary memories) deal preferentially with negative or traumatic material. No such difference between the two types of recall is expected in the basic mechanisms view. Fourth, for the special mechanisms view, involuntary recall involves more sensory and emotional reliving of traumatic material than voluntary recall. For the basic mechanisms view, differences in emotional reliving are not specific to traumatic material but apply to involuntary versus voluntary recall in general. Fifth, according to the DSM-IV-TR definition (American Psychiatric Association, 2000), the A1 and A2 criteria are neces- sary for the development of PTSD symptoms. The special mechanisms view does not question this assumption, whereas the basic mechanisms view holds that properties of the memory of the event rather than the $\mathrm{A} 1$ and $\mathrm{A} 2$ criteria of the event itself will predict PTSD symptoms (Rubin et al., in press). Thus, individual differences factors influencing the availability of the memory (such as personality and temperament) will have a well-specified role to play.

\section{The Present Studies}

We present results from three studies designed to disentangle the special and basic mechanisms view. Study 1 addresses voluntary memory for the traumatic events as well as "control" autobiographical memories in individuals with high versus low levels of PTSD symptoms. It also addresses differences in personality and other individual attributes in the high and low PTSD symptom group. Study 2 addresses involuntary and voluntary memories of autobiographical memories in the same individuals using diaries to record involuntary memories as they occur. Study 3 is a replication of some of the findings in a new sample not selected to vary in PTSD symptom severity and an investigation of emotional intensity as an individual differences variable.

\section{A Note on Design}

According to the official diagnosis of PTSD and the special mechanisms view, PTSD differentially affects memories for traumatic events as opposed to everyday events and differentially affects memories recalled involuntarily as opposed to voluntarily. Thus, a full understanding of the role of autobiographical memory in PTSD requires at a minimum the measurement of the many properties of autobiographical memory known or suspected of being affected by PTSD in people with and without PTSD symptoms, for voluntary and involuntary memories, of normal and traumatic events. That is, as shown in Figure 1, a 2 (PTSD symptoms or not) $\times 2$ (involuntary vs. voluntary retrieval of the memories) $\times 2$ (traumatic vs. everyday events) design is needed with multiple properties of memories measured in each of the eight cells or conditions. Although the DSM diagnosis and theories representing the special mechanisms view expect memories in each of these eight conditions to differ systematically from one another, to our knowledge, this study is the first to begin a comprehensive investigation of the eight conditions. In fact, to our knowledge, our group is the only one to present data on involuntary autobiographical memories in

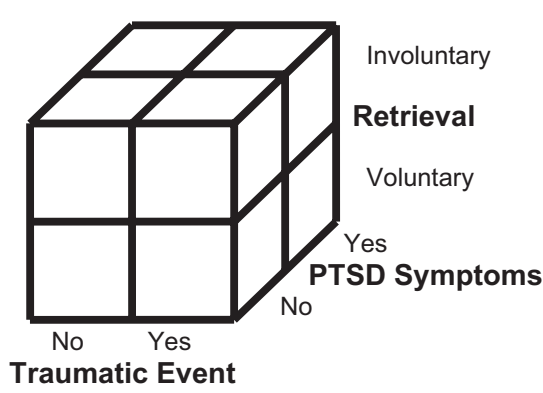

Figure 1. Schematic of the design needed and used to more fully explore the effects of posttraumatic stress disorder (PTSD) on memory. 
people varying in PTSD symptom severity obtained as they occur, as opposed to retrospectively, which provides a more accurate indication of ongoing processes (Ericsson \& Simon, 1993). The three dichotomies shown in Figure 1 provide for easier exposition, but a more continuous design varying PTSD symptom severity is more useful for scientific purposes. In particular, it allows us to investigate individual differences factors that have been related to PTSD in one continuous sample rather than in two categories of participants. In addition, pursuing the basic mechanisms view, we ask how these individual differences factors correlate with the different classes of symptoms of PTSD as well as the properties of autobiographical memory. As a first comprehensive study, for theoretical, practical, and ethical reasons, we begin with undergraduates who vary in PTSD symptom severity and allow stressful as well as traumatic events, though we are now following this study with a more varied, clinically diagnosed sample.

\section{A Theoretically Grounded Inventory of Autobiographical Memory}

We use the basic-systems model of autobiographical memory (Rubin, 2005, 2006; Rubin, Schrauf, \& Greenberg, 2003) to measure the properties of autobiographical memories in a comprehensive fashion. According to the model, the mind and brain are divided into basic systems. These include separate systems for each of the senses, spatial imagery, language, emotion, and narrative. Two systems help to integrate the others: a medial-temporal lobe explicit-memory system that binds all aspects of an autobiographical memory that are present at the same time in a fairly automatic way, and a frontal lobe search-and-retrieval system that selects the most relevant aspects of a network of activations and often operates in a more conscious, directed manner. Each system has a substantial intellectual history including studies involving neuroanatomy, neuropsychology, neuroimaging, cognitiveexperimental psychology, and individual differences research.

Here we use the basic-systems model to provide a welldocumented inventory of the basic properties of autobiographical memory so that we can measure them all. That is, we are taking a giant step backward from the assumptions commonly made in theories of PTSD and are measuring all the basic properties of autobiographical memory, not just those that are thought to be important to PTSD. However, we are using those theories and other observations and results that come from the study of PTSD to emphasize particular properties, including emotion and narrative coherence by increasing the number of rating scales about them. To do this, we use a set of questions based on the basic-systems model, the Autobiographical Memory Questionnaire (AMQ), to ask participants about autobiographical memories as they are recalling them. The set of questions used here is given in Table 1. These and similar questions have been used extensively in earlier studies of autobiographical memory, and so we know a great deal about how these ratings normally function and relate to each other (Rubin, Schrauf, \& Greenberg, 2003, 2004; Rubin, Schrauf, Gulgoz, \& Naka, 2007; Rubin \& Siegler, 2004; Sheen, Kemp, \& Rubin, 2001). In addition to studies with healthy control participants, the AMQ has been used for more and less stressful memories in combat veterans diagnosed with PTSD (Rubin, Feldman, \& Beckham, 2003), for stressful memories of participants who
Table 1

Autobiographical Memory Questionnaire Variables

\begin{tabular}{|c|c|}
\hline Variable & Brief description of rating scales \\
\hline \multicolumn{2}{|c|}{ Sensory component processes } \\
\hline See & $\begin{array}{l}\text { While remembering the event, I can } \\
\text { see mind. }\end{array}$ \\
\hline Field/observer & $\begin{array}{l}\text { I see it out of my own eyes rather } \\
\text { than those of an outside observer. }\end{array}$ \\
\hline Setting & $\begin{array}{l}\text { While remembering the event, I } \\
\text { know the setting where it } \\
\text { occurred. }\end{array}$ \\
\hline Hear & $\begin{array}{l}\text { While remembering the event, I can } \\
\text { hear it in my mind. }\end{array}$ \\
\hline Smell & $\begin{array}{l}\text { While remembering the event, I can } \\
\text { smell it. }\end{array}$ \\
\hline \multicolumn{2}{|c|}{ Emotional component processes } \\
\hline Valence & $\begin{array}{l}\text { While remembering, the emotions } \\
\text { are extremely negative or } \\
\text { positive. }\end{array}$ \\
\hline Intensity & $\begin{array}{l}\text { While remembering, the emotions } \\
\text { that I feel are extremely intense. }\end{array}$ \\
\hline Reaction & $\begin{array}{l}\text { I had a physical reaction (laughed, } \\
\text { felt tense, sweaty, heart pound). }\end{array}$ \\
\hline Mood change ${ }^{a}$ & The memory changed my mood. \\
\hline \multicolumn{2}{|c|}{$\begin{array}{l}\text { Language and narrative } \\
\text { component processes }\end{array}$} \\
\hline In words & $\begin{array}{l}\text { While remembering the event, it } \\
\text { comes to me in words. }\end{array}$ \\
\hline Story & $\begin{array}{l}\text { It comes to me in words or in } \\
\text { pictures as a coherent story. }\end{array}$ \\
\hline Pieces & $\begin{array}{l}\text { My memory comes to me in pieces } \\
\text { with missing bits. }\end{array}$ \\
\hline Life story & $\begin{array}{l}\text { The event in my memory is a } \\
\text { central part of my life story. }\end{array}$ \\
\hline
\end{tabular}

Reported properties of events or memories

Rehearsal

Involuntary

Specific

Merged/extended

Age of memory

Cued by

Trauma related

Metacognitive judgments of recollection and belief Reliving

Belief

Since it happened, I have thought or talked about this event.

This memory has come to me out of the blue, without my trying.

The event occurred once at one particular time (within a day) and place.

A merging of events versus a longer continuous extended event.

Please date the memory (month/ day/year) [calculated from test date].

Was this memory cued by the environment, thoughts, a mix, or voluntary.

The event is related to or about one of the three stressful events I listed.

While remembering the event, I feel as though I am reliving it.

I believe the event in my memory really occurred-not imagined.

${ }^{\text {a }}$ This question was included only in Study 2.

varied in the severity of their PTSD symptoms (Berntsen, Willert, \& Rubin, 2003), and to compare autobiographical memory in various anxiety disorders (Wenzel, Pinna, \& Rubin, 2004). More recently, we have begun using the ratings combined with neuro- 
psychological methods (Greenberg, Eacott, Brechin, \& Rubin, 2005) and functional magnetic resonance imaging (Daselaar et al., 2008).

\section{Study 1: Voluntary Memories}

\section{Method}

\section{Participants}

Over four semesters, 717 Duke undergraduate students provided scores for the PTSD Check List (PCL; Weathers, Litz, Huska, \& Keane, 1994) in large group screening sessions for a specific, dated event. For the PCL, participants rate, on a 1 (not at all) to 5 (extremely) scale, how much a stressful or traumatic event has produced each of the official $17 \mathrm{~B}, \mathrm{C}$, and D symptoms of PTSD during the past month. The minimum score is thus 17 . The mean of all 717 participants was $30.80(S D=11.87, M d n=28$, minimum $=17$, maximum $=84$ ). To be selected for the study, participants had to have a PCL score below 25 for the low PCL group or above 40 for the high PCL group. These cutoffs included $39.33 \%$ and $18.69 \%$ of the screening-session sample, respectively. We made the low PCL range broader because we wanted a control sample representative of the population without symptoms that could qualify for PTSD. That is, we did not want our results to be driven by possible peculiarities that might exist in participants who scored extremely low as opposed to just well below threshold on PTSD symptom severity. To remain in the low group of the study, at the first experimental session, which was separated from the screening session by between 1 and 2 weeks, the participant had to score below 34 on a second PCL (i.e., below an average score of 2 on each of the 17 items). To remain in the high group of the study, participants had to score at or above 34 on the new PCL, and the negative event from the group-screening session had to be at least 1 month prior. One month is the minimum delay for a diagnosis of PTSD, because many acute reactions to stress resolve over that period. We therefore adopted that period to be consistent with the diagnosis and to reduce the effects of the negative event fading dramatically because of normal forgetting over the duration of the testing. In this process, we lost 10 participants: 4 whose scores dropped and 6 whose scores increased.

This two-step screening procedure resulted in 55 participants in the low group ( 32 women, 23 men; mean age $=18.53, S D=0.77$ ) and 60 in the high group ( 39 women, 21 men; mean age $=18.83$, $S D=1.17)$. The correlation between the two administrations of the PCL in these 115 participants was .90. In the large screening sessions, the low and high groups had PCL scores below 25 or above 40, respectively. In the first experimental sessions, they had PCL scores below $34(M d n=23, M=23.81, S D=4.01$, minimum $=18$, maximum $=33)$ or at or above $34(M d n=45.5$, $M=47.35, S D=9.19$, minimum $=34$, maximum $=70$ ), respectively. Thus, the division into groups is based on two highly correlated test results at least 1 week apart. Although we started out with a dichotomous selection criteria with scores between 25 and 40 excluded, our final sample includes a continuous range of scores. Dividing the scores on the second PCL into bins of 5 starting with the minimum possible score of 17 (e.g., 17-21, $22-26,27-31, \ldots 67-71)$ there are $17,24,10,11,10,15,9,11,3$, 1 , and 4 participants in each bin. We therefore use the score from the second PCL test, which occurred closer in time to the rest of the testing, as our continuous measure. We do analyses based both on a dichotomous low versus high PCL group and on the PCL score as a continuous variable. In comparison to an unselected sample of undergraduates, our sample has many fewer participants with low and middle scores on the PCL and thus much more variance in the PCL scores. The correlations we obtain here should therefore be higher than would those from an unselected sample. Nonetheless, the distribution is not atypical for studies of PTSD symptom severity, depression, or other clinical measures and is a continuous and nearly uniform distribution over most of its range. Study 3 will investigate effects of our use of a fairly uniform distribution by comparing it with a large comparison sample drawn from the same population, but without any restrictions placed on the PCL scores.

The $D S M-I V-T R$ A criteria are not part of many of the widely used tests of symptom severity, including those we used. Thus, our selection procedures allowed participants whose most stressful event was not an A trauma into our study. We did this to investigate the A criteria. Following the basic mechanisms view, we want to know what happens when stressful events are not traumas as defined by the DSM. Therefore, in addition to our test of symptom severity, we asked individuals whether each of their three most stressful events met the A1 and the A2 criteria. In this way, we can examine the effects of having at least one stressful event that meets the full A criterion and can also have 4-point scales for the A1 and A2 criteria indicating whether $0,1,2$, or 3 of a participant's three most stressful events met the criteria.

A score of 44 is the best predictive cutoff for the PCL if other criteria of PTSD are met (Blanchard, Jones-Alexander, Buckley, \& Foneris, 1996). Of the 60 participants in the high PCL group, 35 had PCL scores at or above 44 on the second PCL test. A score of 40 is the best predictive cutoff for the Davidson Trauma Scale (DTS; Davidson et al., 1997). There were 36 participants at or above this score. Thus, roughly half of the participants in the high PCL group had PTSD severity scores in the range of people who are diagnosed with PTSD. Using these minimum scores and the requirement that the participants had to report at least one of their three negative events as meeting both the A1 and A2 criteria, 22 of the participants in the high PCL group probably would meet the PTSD diagnosis in a formal diagnosis using the PCL cutoff and 23 using the DTS cutoff. Thus, a third of our participants in the high PCL group would be likely to have PTSD if formally evaluated. However, a diagnosis of PTSD can be obtained only from a licensed clinician who conducts a personal interview, which was not done here.

\section{Materials}

Autobiographical Memory Questionnaire (AMQ). The AMQ is a set of questions that vary slightly depending on the theoretical questions being asked. We used items from the AMQ to measure properties of each nominated memory. A list of the items is shown in Table 1. All items used a 7-point scale, except once and merged, which are derived from a 3-point scale. The scales are considered individually rather than being summed because they measure different aspects of autobiographical memory, such as the vividness of visual imagery and the intensity of emotion. In the Results section, where we show that individual scales are empirically 
related as well as conceptually related, we consider composite scores.

Beck Depression Index (BDI). The BDI-II (Beck, Steer, \& Brown, 1996) is probably the most widely used test of depression. There are 21 items rated on a 0 to 3 scale, and the sum score is reported.

Centrality of Event Scale (CES). The CES (Berntsen \& Rubin, 2006c, 2007) measures the extent to which a traumatic memory forms a central component of personal identity - a turning point in the life story and a reference point for everyday inferences. The CES consists of 20 items rated on 5-point scales $(1=$ totally disagree; $5=$ totally agree) in relation to the most stressful or traumatic event in the person's life. The mean rating is reported. The CES is positively correlated with severity of PTSD symptoms, which remain significant even when controlling for measures of anxiety, depression, dissociation, and self-consciousness (Berntsen \& Rubin, 2006c, 2007).

Davidson Trauma Scale (DTS). Similar to other current tests of PTSD, the DTS (Davidson et al., 1997) sums values for each of the 17 symptoms of PTSD in the official DSM diagnosis. It was specifically developed as a self-rating scale. Each symptom is rated twice: once for frequency and once for severity using a 0 to 4 scale. As a continuous measure of severity, the scale had a correlation of .78 with a clinician administered PTSD scale.

Dissociative Experiences Scale (DES). The DES (Bernstein \& Putnam, 1986; Carlson \& Putnam, 1993) is a standardized test of dissociation and one of the most commonly used tests in individual difference studies of autobiographical memory (Read \& Winograd, 1998). The test has 28 items that are rated on a continuous scale from $0 \%$ to $100 \%$.

Life script measures: Life script prevalence, life script importance, life script valence, and life script typicality. These measures are based on a series of studies by Berntsen and Rubin and others (Berntsen \& Rubin, 2002, 2004; Erdoğan, Baran, Alvar, Taş, \& Tekcan, 2008; Rubin \& Berntsen, 2003). They include measures of how semantic knowledge about the expected life course is affected by other variables. Participants are asked to

Imagine a quite ordinary infant (of your own gender). It cannot be a specific infant that you know, but a prototypical infant in our culture with a quite ordinary life course ahead. Your task is to write down the seven most important events that you imagine are most likely to take place in this prototypical infant's life, from birth to death. Write the events in the same order as they come to your mind. Give each event a short title that specifies its content.

They are then asked the following questions. "How common is the event: Out of a hundred people how many will experience this event at least once during their life?" "How important is the event?" (scored from $1=$ unimportant to 7 = of greatest importance). "At what age is the event expected to take place?" "Is the event emotionally positive or negative?" (scored from $-3=$ very negative to 0 to $+3=$ very positive). The average values of these questions provide scores for life script prevalence, life script importance, and life script valence. In addition, life script typicality is the sum of the number of undergraduates in a sample of 100 undergraduates (Rubin, Berntsen, \& Hutson, 2007) who listed each of the 7 events more than three times. It provides a measure of how similar the individual's life script is to a standard life script of 100 peers. If an individual listed the most commonly listed 7 events (which were marriage, 92; having children, 77; beginning or graduating college, 54; beginning school, 48; beginning or graduating high school, 46; first job, 38; and begin talking, 29), they would have a sum of 384. For life script typicality, two independent raters classified the events. Out of 805 events ( 7 events from each of 115 participants), there were 26 responses in which the participants used more than 1 event on a line (e.g., "begin walking, talking," "marriage, children," and "college, leaving home"). For these responses the highest ranking event was chosen. An additional 36 responses were classified differently by the two raters, and these discrepancies were resolved by a third judge.

NEO Personality Inventory (NEO). The NEO (Costa \& McCrae, 1992) provides a comprehensive assessment of adult personality with five domains and 6 facets within each domain. The instrument embodies a conceptual model based on factor analytic research on the structure of personality. It was designed to reflect the traits, in natural language, that cover the full range of normal behaviors, thoughts, and feelings. Individuals make judgments about typical past actions or thoughts in order to agree or disagree with a series of 240 statements ( 8 for each of the 30 facets) such as "I am not a worrier," "I rarely experience strong emotions," and "I tend to assume the best about people" (Costa \& McCrae, 1992). Thus, the personality description provided is based on personal semantic memory. Unlike the other tests used here, for the NEO the scales for the domains and facets are all $\mathrm{T}$ scores based on standardized norms. Thus, 50 is the mean and 10 is the standard deviation of the standard comparison population.

$P C L$. The PCL (described in more detail above;Weathers et al., 1994), like the Davidson Trauma Scale, has participants rate the 17 official symptoms of PTSD. It uses a 1 to 5 scale, so the minimum score is 17 .

\section{Procedure}

One to two weeks after the large group screening sessions, participants took part in three experimental sessions. The sessions were always on separate days and were an average of 2 days apart. In the first experimental session, the participants did the AMQ for 15 cue words, then the life script measures, and finally the PCL. In the second session, they did the AMQ for the seven most important, three most negative, and three most positive events in their lives; the CES; and the DTS. They also indicated the presence of $\mathrm{A} 1$ and $\mathrm{A} 2$ symptoms for the three most negative events. In the third session, they did the BDI, DES, and NEO.

The procedure for the autobiographical memories was as follows. Participants generated autobiographical memories to the following cues: 15 word cues intended to provide a sample of autobiographical memory as neutral as possible with regard to narrative importance and emotional impact, seven most important events, three most negatively stressful or traumatic events, and three most positive events. The 15 cue words were common high imagery words we have used previously: city, dress, fire, horse, kiss, lake, love, mother, mountain, ocean, party, plant, poetry, sick, and wine. The instructions for the important events were as follows:

Please record the seven most important events in your life for which you have an autobiographical memory, that is a memory that is of a specific event that occurred at a specific time and place. The memory itself should be uncensored, but the description you record need be 
intelligible only to you and should not contain anything illegal or embarrassing.

The requests for emotional events were similar but substituted the following text: "Please record the three most negatively stressful or traumatic events in you life" and "please record the three most positive events in your life." For the most negative and most positive events, participants were given the following instructions:

If one or more of the seven important events listed earlier is one of your three most negatively stressful or traumatic events (or three most positive events), just record it again here, draw a single line through it in the important memories, and replace it with another important memory in the space given to the right of the line.

Thus, the seven most important events had any events that would qualify for the three most positive or negative events removed and replaced by what would have to be events of less extreme emotions. We did this so we would have independent events in each category. We also reconstructed the original seven important events before any were moved to the positive or negative category and used measures based on these events to provide an index of the individuals' life story that can be contrasted to their life script. For each of the most negative events, the participants were asked if they met the A1 and A2 symptoms of the PTSD diagnosis: (A1) "Did you experience, witness, or were you confronted with an event that involved actual or threatened death or serious injury, or threat to the physical integrity of yourself or others?"; (A2) "Did your response involve intense fear, helplessness, or horror?"

\section{Results}

We use two forms of analysis: analyses of variance (ANOVAs) based on the dichotomous high and low PCL groups and correlational analyses based on the continuous variables we measured. We use the $p<.05$ level uncorrected for multiple comparisons for two reasons. First, we want to present statistically significant results favoring the general mechanisms view and no statistically significant results favoring the special mechanisms view. Thus, we want to keep the .05 level to show no effect for the special mechanisms view. Second, we are interested in showing the same pattern of results over more than one measure of a concept and over more than one experiment, rather than focusing on each significant result. We first describe findings on individual differences in relation to trauma and symptom severity. We next examine the relation between symptom severity and voluntary autobiographical memory.

\section{Trauma and Symptom Severity}

The means for the A symptoms, the PCL, and DTS for the low and high PCL groups; a $t$ test comparing the means of the two groups; and correlations between the PCL measure and each variable are shown in Table 2. Most participants reported that at least one of their three most negative events met the A1 and A2 symptoms of PTSD, and there was no statistically significant difference in this measure between the high and low PCL groups. There was no difference between the groups in reports of exposure to A1 traumatic events, but the high PCL group reported more events with A2 emotions. Thus, the events did not differ as a function of PTSD symptom severity, but the reaction to them did.

\section{Individual Differences Measures}

Table 2 also shows the means and standard deviations for all of the individual differences measures. As expected from earlier studies, there are large mean differences on the BDI, CES, DES, and DTS and Neuroticism from the NEO. Figure 2 plots these variables as a function of the PCL scores to ensure that the effects are linear. For this purpose, the PCL was divided into the bins reported when the distribution of scores was given in the procedure section, except that to try to ensure a minimum of 10 observations per bin to provide a stable measure, the two bins from 47 to 56 and the three bins from 57 to 71 were combined.

Measures of the life script do not show differences with the PCL group except for valence, and there only for the correlation. Thus, knowledge of the generic life script shows at most minimal changes. Measures of the life story, that is, events from the participants' own lives not those of hypothetical average people, were obtained from the ratings given to the original seven most important events in each participant's life before any of the most negative or positive memories were replaced by other important events. Emotional intensity, as measured by intensity and reaction, showed substantial effects.

For the NEO, we report on the five domains rather than the facets, limiting our presentation of the data of all 30 facets to supporting information. Neuroticism had the largest correlation with the PCL in the expected direction of increases in the PCL with increases in Neuroticism. Extroversion and Conscientiousness had smaller, negative correlations, which indicated a protective role for these personality traits. All 6 facets of the Neuroticism domain had significant correlations at the $p<.001$ level, whereas only 4 of the remaining 24 facets did. These results are consistent with a major role for neuroticism in PTSD symptom severity.

When the PCL was predicted by all the other individual differences tests in Table 2, only three measures entered at the $p<.05$ level, with the following standardized coefficients producing an adjusted $R^{2}$ of .69 : PCL $=.40 \mathrm{DES}+.39 \mathrm{BDI}+.24 \mathrm{CES}$. If the life script and life story from the original seven most important events measures listed in Table 2 were also included, then life story intensity also enters, producing an adjusted $R^{2}$ of .70: PCL $=$ $.39 \mathrm{BDI}+.37 \mathrm{DES}+.23 \mathrm{CES}+.12$ intensity. This suggests that participants who recall and feel emotions in their memories intensely are likely to have higher PTSD symptom severity beyond the effects of depression, dissociation, and centrality of a negative event to their identity. We explore this finding in other analyses.

\section{How PTSD Symptom Severity Relates to Autobiographical Memory Measures}

As outlined in Figure 1, one main purpose of this study was to investigate how properties of autobiographical memory for average and stressful events varied with PTSD symptom severity. The answer is simple for voluntary memory. As shown in Tables 3 and 4 , of the large number of measures chosen to cover the range of processes that are important in autobiographical memory, only a few measures vary as a function of PTSD symptom severity. Moreover, these are the same measures for the autobiographical memories 
Table 2

Individual Differences Measures as a Function of PTSD Symptom Severity

\begin{tabular}{|c|c|c|c|c|c|c|}
\hline \multirow[b]{2}{*}{ Variable } & \multicolumn{2}{|c|}{ Low PCL } & \multicolumn{2}{|c|}{ High PCL } & \multirow[b]{2}{*}{$t(113)$} & \multirow[b]{2}{*}{$r(113)$} \\
\hline & $M$ & $S D$ & $M$ & $S D$ & & \\
\hline \multicolumn{7}{|l|}{ Standardized tests } \\
\hline$\geq 1$ A events $(\%)$ & 56.36 & 50.05 & 66.67 & 47.54 & $1.13^{\mathrm{a}}$ & .02 \\
\hline A1 ( $\%$ of 3 events) & 36.36 & 30.27 & 36.67 & 31.71 & 0.05 & -.02 \\
\hline A2 ( $\%$ of 3 events) & 50.91 & 32.62 & 72.78 & 28.45 & $3.84^{* * * *}$ & $.32^{* * * * *}$ \\
\hline BDI & 4.33 & 3.61 & 15.12 & 12.41 & $6.21^{* * * * * * *}$ & $.70^{* * * * * * *}$ \\
\hline CES & 2.83 & 0.76 & 3.95 & 0.73 & $7.99^{* * * * * *}$ & $.56^{\text {******** }}$ \\
\hline DES & 7.61 & 4.93 & 22.93 & 12.50 & $8.50^{* * * * * *}$ & $.70^{* * * * * *}$ \\
\hline \multicolumn{7}{|l|}{ DTS } \\
\hline Frequency & 5.07 & 4.61 & 24.67 & 12.34 & $11.08^{* * * * * *}$ & $.83^{* * * * *}$ \\
\hline Severity & 4.85 & 5.05 & 25.77 & 12.70 & $11.41^{\text {******* }}$ & $.83^{* * * * *}$ \\
\hline Total & 9.93 & 9.25 & 50.43 & 24.16 & $11.67^{* * * * * *}$ & $.84^{* * * * *}$ \\
\hline PCL & 23.81 & 4.01 & 47.35 & 9.19 & & \\
\hline \multicolumn{7}{|l|}{ Life script } \\
\hline Prevalence & 82.56 & 8.63 & 83.49 & 7.91 & 0.61 & .07 \\
\hline Importance & 5.78 & 0.60 & 5.88 & 0.64 & 0.91 & .11 \\
\hline Valence & 1.68 & 0.78 & 1.41 & 0.75 & -1.88 & $-.21^{*}$ \\
\hline Typicality & 39.57 & 9.97 & 37.77 & 9.88 & -0.97 & -.04 \\
\hline \multicolumn{7}{|c|}{$\begin{array}{l}\text { Life story from AMQ ratings of original } \\
7 \text { most important events }\end{array}$} \\
\hline Importance ${ }^{\mathrm{b}}$ & 5.31 & 0.92 & 5.50 & 1.02 & 1.04 & .17 \\
\hline Valence $0.80(1.00)$ & 0.51 & 1.11 & -1.48 & $-.19^{*}$ & & \\
\hline Intensity & 4.29 & 0.99 & 5.01 & 1.04 & $3.79^{* * * *}$ & $.38^{* * * * *}$ \\
\hline Reaction & 2.74 & 1.21 & 3.73 & 1.19 & $4.44^{* * * * *}$ & $.39^{* * * * *}$ \\
\hline \multicolumn{7}{|l|}{ NEO domains (all) } \\
\hline Neuroticism & 42.95 & 9.64 & 57.91 & 12.00 & $7.28^{* * * * *}$ & $.62^{* * * * *}$ \\
\hline Extroversion & 50.66 & 11.23 & 44.37 & 13.95 & $-2.63^{*}$ & $-.33^{* * * *}$ \\
\hline Openness & 48.96 & 10.01 & 53.34 & 9.56 & $2.39^{*}$ & $.19^{*}$ \\
\hline Agreeableness & 51.87 & 15.01 & 51.46 & 11.75 & -0.17 & -.05 \\
\hline Conscientiousness & 54.33 & 10.67 & 47.90 & 11.90 & $-3.03^{*}$ & $-.33^{* * * *}$ \\
\hline Gender $(\%)$ & 58.18 & 49.78 & 65.00 & 48.10 & 0.75 & .08 \\
\hline
\end{tabular}

Note. $\quad$ For gender, male $=0$, female $=1 . \mathrm{PTSD}=$ posttraumatic stress disorder; PCL $=$ PTSD Check List; A, A1, and A2 = Diagnostic and Statistical Manual of Mental Disorders criteria for PTSD; BDI = Beck Depression Inventory; CES $=$ Centrality of Event Scale; DES $=$ Dissociative Experiences Scale; DTS $=$ Davidson Trauma Scale; AMQ = Autobiographical Memory Questionnaire; NEO = NEO Personality Inventory.

${ }^{a}$ A more appropriate statistic is, $\chi^{2}(1)=1.29, p=.26$. ${ }^{\mathrm{b}}$ Here importance is the life story rating.

${ }^{*} p<.05 .{ }^{* * * *} p<.001 .{ }^{* * * * *} p<.0001$.

cued by words, which are intended to sample a broad range of highly available autobiographical memories, and for autobiographical memories of the most important, most positive, and most negative events. As shown in the tables, the means for life story, which measure how central the event in the memory is to the participant's life story, are much lower for the word-cued memories (mean of 2.57) than for the other three types of cues (mean of 5.00). Thus, the word-cued memories are considerably less important and represent a broader sample of events. Thus, contrary to the special mechanisms view, not just memory for the most negative events varies as a function of high versus low PTSD symptom levels. Certain measures of autobiographical memory in general are affected, suggesting that individual memory styles may be related to the development of PTSD, consistent with the basic mechanisms view. These measures are the sensory measures of hear and smell, the emotional intensity measures of intensity and reaction, centrality to the life story, and the voluntary and involuntary availability measures of rehearsal and involuntary. These seven measures all show significant differences for the most negative and for the word-cued memories, and five of the seven are significant for the important memories. For the most positive memories only reaction is consistently significant. Moreover, if we look for all other significant differences related to PCL scores in the remaining 48 tests ( 12 measures $\times 4$ categories), only two more appear for the correlations and neither is significant for the $t$ test. Thus, we have variables that are affected by PTSD symptom severity and those that are not, rather than a continuum that is arbitrarily divided on the basis of the power available. The differences are smaller for the most positive memories and larger for the most negative memories, indicating a role for the valence of the memories. We test this statistically by using ANOVAs to look for interactions in a later section.

\section{Increases in Emotional Intensity, Availability, and Importance to the Life Story as Predisposing Factors}

There are substantial correlations among the PCL scores and measures of intensity, availability, and importance to the life story for the word-cued, important, and negative memories and for measures of intensity for the positive memories, as shown in Tables 3 and 4. There are two possible explanations for this, and both could be operating to varying degrees. The first is that having 


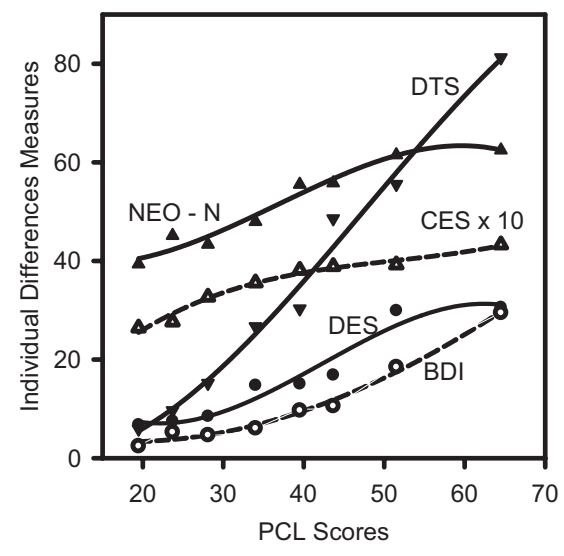

Figure 2. The increase in scores on standard individual differences tests as a function of posttraumatic stress disorder (PTSD) symptom severity as measured by the PTSD Check List (PCL). BDI = Beck Depression Index; $\mathrm{CES}=$ Centrality of Event Scale; DES = Dissociate Experiences Scale; DTS $=$ Davidson Trauma Scale, NEO-N = Neuroticism subscale of the NEO Personality Inventory.

a negative event that leads to PTSD symptoms causes the change in these AMQ measures. The second is that these AMQ measures are predisposing conditions that make PTSD symptoms more likely in individuals when a negative event is encountered. A prospective study in which individuals are tested before they experience an extremely stressful event is ideal to disentangle these two alternatives, but the undergraduate sample tested here provides strong evidence favoring the predisposing conditions explanation. As shown in Table 2, over half of our participants have experienced at least one A event, and the proportion does not differ significantly between the high and low PCL samples. In addition, most of the participants do not have symptoms that are severe enough for them to be diagnosed with PTSD. If the correlations we observe hold for individuals with PCL scores below the statistical cutoff for PTSD, then in these individuals we cannot claim that the increase in other measures are caused by PTSD. We start by plotting, in Figure 3, the two measures of emotional intensity, intensity and reaction, for the three negative memories because they had the largest correlations in Tables 2 and 3 and therefore the least amount of noise. We use the same bins of 5 units on the PCL that were reported earlier to provide the distribution of scores and were used in Figure 2. The plots are fairly linear and show similar patterns for the 4 points below a PCL score of 42 and the 3 points above a PCL score of 41 , where 44 is a statistical cutoff for PTSD.

If we return to the raw data, not grouped for the plot, the correlations of the PCL with intensity, reaction, life story, rehearsal, and involuntary for the three most negative memories are $.39, .47, .30, .23$, and .44 , respectively. For the 80 individuals with PCL scores below 44, the same correlations are reduced somewhat as might be expected from the restricted range of the PCL to .29, $.23, .09, .01$, and .30 . For the 35 individuals with PCL scores above 43 , the correlations are reduced more substantially to $-.06, .02$, $.15, .01$, and .02 , respectively. Thus, the correlation is not stronger in people who might have PTSD. Because these correlations are for the three negative memories, they might confound the general measures with the severity of the negative events. The 15 wordcued memories, which were collected before any of the other memories and which are intended to provide a fairly neutral sample of autobiographical memories (Crovitz \& Schiffman, 1974; Galton, 1879), provide a fairer test. The correlations of the PCL with intensity, reaction, life story, rehearsal, and involuntary are $.33, .33, .28, .21$, and .25 , respectively. For the 80 individuals with PCL scores below 44, the same correlations are $.39, .28, .26, .15$,

Table 3

Relation of PTSD Symptom Severity and AMQ Variables for High and Low PCL Groups for Word-Cued and Important Events

\begin{tabular}{|c|c|c|c|c|c|c|c|c|}
\hline \multirow[b]{2}{*}{ Variable } & \multicolumn{4}{|c|}{ Word cued } & \multicolumn{4}{|c|}{ Important } \\
\hline & Low $(M)$ & High $(M)$ & $t(113)$ & $r(113)$ & Low $(M)$ & High $(M)$ & $t(113)$ & $r(113)$ \\
\hline Reliving & 4.35 & 4.46 & 0.64 & -.02 & 4.65 & 4.67 & 0.13 & -.02 \\
\hline Belief & 5.74 & 5.63 & -0.76 & -.12 & 5.96 & 5.84 & -0.74 & -.10 \\
\hline See & 5.47 & 5.43 & -0.29 & -.05 & 5.48 & 5.42 & -0.36 & -.03 \\
\hline Field & 4.89 & 4.52 & 1.92 & $-.20^{*}$ & 4.81 & 4.79 & -0.08 & .06 \\
\hline Setting & 5.42 & 5.46 & 0.29 & -.04 & 5.53 & 5.43 & -0.62 & -.06 \\
\hline Hear & 3.47 & 3.90 & $2.17^{*}$ & $.19^{*}$ & 3.43 & 3.93 & $2.12^{*}$ & $.22^{*}$ \\
\hline Smell & 2.22 & 2.62 & $2.08^{*}$ & $.21^{*}$ & 1.83 & 1.92 & 0.46 & .14 \\
\hline Valence & 0.73 & 0.60 & -0.21 & -.03 & 1.05 & 0.89 & -0.94 & -.15 \\
\hline Intensity & 3.37 & 4.02 & $3.88^{* * * *}$ & $.33^{* * * *}$ & 3.83 & 4.47 & $3.42^{\text {***** }}$ & $.33^{* * * * *}$ \\
\hline Reaction & 2.55 & 3.26 & $3.80^{* * * * *}$ & $.33^{* * * *}$ & 2.54 & 3.22 & $3.08^{* * *}$ & $.24^{* * *}$ \\
\hline In words & 2.57 & 2.66 & 0.39 & .03 & 2.70 & 2.87 & 0.62 & .02 \\
\hline Story & 4.03 & 4.11 & 0.45 & -.02 & 4.40 & 4.51 & 0.56 & .00 \\
\hline Pieces & 3.96 & 3.91 & -0.31 & .07 & 3.64 & 3.68 & 0.16 & .09 \\
\hline Life story & 2.32 & 2.79 & $3.43^{* * * *}$ & $.28^{* *}$ & 4.88 & 5.06 & 0.91 & .14 \\
\hline Rehearsal & 3.16 & 3.41 & $2.16^{*}$ & $.21^{*}$ & 3.92 & 4.29 & $2.39^{*}$ & $.21^{*}$ \\
\hline Involuntary & 2.45 & 2.87 & $2.98^{* * *}$ & $.25^{* *}$ & 2.60 & 3.30 & $3.45^{* * * *}$ & $.26^{* * *}$ \\
\hline Specific & 0.72 & 0.68 & -1.64 & -.06 & 0.75 & 0.67 & -1.53 & -.17 \\
\hline Merged & 0.32 & 0.30 & -0.40 & .06 & 0.48 & 0.39 & -1.22 & -.06 \\
\hline Age of memory & 3.86 & 4.26 & 1.34 & $.21^{*}$ & 4.38 & 4.26 & -1.34 & .04 \\
\hline
\end{tabular}

Note. $\quad$ PTSD $=$ posttraumatic stress disorder; AMQ $=$ Autobiographical Memory Questionnaire; PCL $=$ PTSD Check List.

${ }^{*} p<.05 .{ }^{* * *} p<.01 .{ }^{* * *} p<.001$. 
Table 4

Relation of PTSD Symptom Severity and AMQ Variables for High and Low PCL Groups for Positive and Negative Events

\begin{tabular}{|c|c|c|c|c|c|c|c|c|}
\hline \multirow[b]{2}{*}{ Variable } & \multicolumn{4}{|c|}{ Positive } & \multicolumn{4}{|c|}{ Negative } \\
\hline & Low $(M)$ & High $(M)$ & $t(113)$ & $r(113)$ & Low $(M)$ & High $(M)$ & $t(113)$ & $r(113)$ \\
\hline Reliving & 5.40 & $5.33-$ & 0.37 & -.10 & 5.16 & 5.29 & 0.66 & .07 \\
\hline Belief & 6.23 & 6.16 & -0.49 & -.07 & 6.19 & 5.95 & -1.37 & -.13 \\
\hline See & 5.97 & 5.88 & -0.47 & -.05 & 5.62 & 5.81 & 0.94 & .10 \\
\hline Field & 5.16 & 5.48 & 1.22 & .04 & 4.94 & 4.55 & -1.22 & -.09 \\
\hline Setting & 6.07 & 5.93 & -0.74 & -.10 & 5.67 & 5.79 & 0.67 & .10 \\
\hline Hear & 4.53 & 4.78 & 0.95 & .08 & 4.16 & 4.81 & $2.31^{*}$ & $.20^{*}$ \\
\hline Smell & 2.13 & 2.34 & 0.93 & .12 & 1.72 & 2.05 & 1.48 & $.25^{\text {*** }}$ \\
\hline Valence & 2.45 & 2.43 & -0.16 & -.01 & -2.37 & -2.55 & -1.85 & -.18 \\
\hline Intensity & 4.55 & 4.90 & 1.47 & $.19^{*}$ & 5.18 & 6.02 & $4.93^{* * * * * *}$ & $.39^{* * * * * * *}$ \\
\hline Reaction & 2.85 & 3.71 & $3.22^{* *}$ & $.26^{* * *}$ & 3.30 & 4.56 & $5.25^{* * * * *}$ & $.47^{* * * * *}$ \\
\hline In words & 2.90 & 2.85 & -0.16 & -.04 & 3.06 & 3.02 & -0.14 & -.03 \\
\hline Story & 5.03 & 5.01 & -0.10 & -.04 & 4.92 & 4.74 & -0.67 & -.04 \\
\hline Pieces & 3.31 & 3.33 & 0.07 & .06 & 3.41 & 3.53 & 0.45 & .07 \\
\hline Life story & 5.05 & 4.97 & -0.32 & .05 & 4.69 & 5.35 & $2.72^{*}$ & $.30^{* * *}$ \\
\hline Rehearsal & 4.56 & 4.44 & -0.57 & -.09 & 4.30 & 4.82 & $2.30^{*}$ & $.23^{*}$ \\
\hline Involuntary & 3.15 & 3.72 & $2.28^{*}$ & .11 & 3.05 & 4.44 & $5.45^{\text {******* }}$ & $.44^{* * * * *}$ \\
\hline Specific & 0.74 & 0.73 & -0.21 & .01 & 0.78 & 0.75 & -0.59 & -.11 \\
\hline Merged & 0.47 & 0.53 & 0.52 & .00 & 0.54 & 0.53 & -0.06 & .00 \\
\hline Age of memory & 2.66 & 2.41 & -0.76 & .00 & 3.69 & 3.94 & 0.68 & .10 \\
\hline
\end{tabular}

Note. $\quad$ PTSD $=$ posttraumatic stress disorder; $\mathrm{AMQ}=$ Autobiographical Memory Questionnaire; PCL $=$ PTSD Check List

${ }^{*} p<.05$. $^{* * *} p<.01$. $^{* * * * *} p<.0001$.

and .28 , respectively, which is not a general reduction. For the 35 individuals with PCL scores above 43, the correlations do reduce to $.16, .20, .07, .11$, and .07 , respectively. These findings are important because they suggest that for our undergraduate sample, intensity, reaction, life story, rehearsal, and involuntary can be viewed more as predisposing conditions than as effects of PTSD. For samples with more severe or chronic traumas, we might also expect changes in these measures caused by PTSD. This result warrants further investigation in a prospective study.

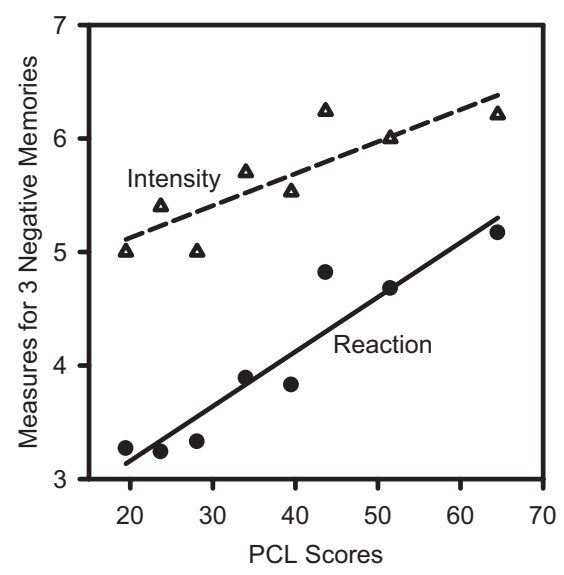

Figure 3. The increase in scores of emotional intensity and physiological reaction ratings for the three most negatively stressful memories, as a function of posttraumatic stress disorder (PTSD) symptom severity as measured by the PTSD Check List (PCL) from Study 1.

\section{Effects of Most Negative Versus Other Types of Events on} Autobiographical Memory Measures

We compared the most negative memories with the word-cued memories to provide a comparison with a broad sampling of memories, with the most important memories to provide a comparison with other important memories but ones that were not among the most emotional, and with the most positive memories to examine the effects of valence. The type of comparison memory was one factor, and PCL group was the other factor. Supporting means and ANOVAs are reported in Table 5. The effects of PCL group were discussed above for each type of event separately. In the ANOVAs shown in Table 5, the effect of PCL group is on values that weight equally the memories of the three negative events and the comparison events and so is not of theoretical interest. Because these findings replicate the basic findings shown in Tables 3 and 4, they are not shown again.

Means for each type of remembered event are shown in Table 5. The table also shows the comparison of the negative events with three possible comparisons: word-cued memories, important memories, and positive memories. The significant effects are generally caused by the negative events having mean ratings that are conceptually higher. For pieces, negative events have lower ratings, which are in the conceptual direction of more coherence, contrary to the special mechanisms view that traumatic memories are fragmented and incoherent. The only exceptions to the three most negative events having statistically higher values come in the word-cued comparison with smell and with comparisons with memories for the three most positive events. There, the ratings for see, setting, and smell are all lower for the most negative events. The lower rating for setting is expected from what is known about tunnel memory, that is, enhanced memory for central details at the 
Table 5

Means and Analyses of Variance for Comparisons of Memories for Negative Events With Word-Cued, Important, and Positive Events

\begin{tabular}{|c|c|c|c|c|c|c|c|c|c|c|}
\hline \multirow[b]{3}{*}{ Variable } & & & & & \multicolumn{6}{|c|}{ Analysis of variance, $F(1,113)$} \\
\hline & \multicolumn{4}{|c|}{ Means for four memory types } & \multicolumn{3}{|c|}{ Comparison: Negative } & \multicolumn{3}{|c|}{ Comparison by PCL interaction } \\
\hline & Word cued & Important & Positive & Negative & Word cued & Important & Positive & Word cued & Important & Positive \\
\hline Reliving & 4.41 & 4.66 & 5.36 & 5.23 & $82.58^{\text {******* }}$ & $39.09^{\text {***** }}$ & 2.15 & 0.02 & 0.35 & 1.12 \\
\hline Belief & 5.68 & 5.90 & 6.19 & 6.06 & $29.01^{* * * * * * * * *}$ & $10.18^{* * *}$ & 3.59 & 0.79 & 1.31 & 1.55 \\
\hline See & 5.45 & 5.45 & 5.92 & 5.72 & $9.43^{* * *}$ & $9.38^{* *}$ & $4.70^{*}$ & 1.75 & 1.96 & 2.01 \\
\hline Field & 4.70 & 4.80 & 5.33 & 4.74 & 0.09 & 0.18 & $17.44^{* * * * * * *}$ & 0.01 & 2.02 & $6.55^{*}$ \\
\hline Setting & 5.44 & 5.48 & 6.00 & 5.73 & $11.12^{\text {*** }}$ & $9.34^{* * *}$ & $8.56^{* * *}$ & 0.23 & 1.92 & 2.06 \\
\hline Hear & 3.69 & 3.69 & 4.66 & 4.50 & $49.69^{* * * * * *}$ & $44.57^{* * * * * *}$ & 1.76 & 0.99 & 0.37 & 2.38 \\
\hline Smell & 2.43 & 1.88 & 2.24 & 1.89 & $27.96^{* * * * * *}$ & 0.00 & $9.99^{* *}$ & 0.12 & 1.84 & 0.24 \\
\hline Valence & 0.66 & 0.97 & 2.44 & -2.47 & $2065.85^{\text {****** }}$ & $1262.88^{* * * * *}$ & $3497.41^{\text {****** }}$ & 0.15 & 0.01 & 0.96 \\
\hline Intensity & 3.71 & 4.17 & 4.73 & 5.62 & $431.59^{* * * * *}$ & $269.52^{* * * * *}$ & $85.59^{* * * * *}$ & 1.24 & 1.42 & $6.96^{* *}$ \\
\hline Reaction & 2.92 & 2.90 & 3.29 & 3.96 & $96.61^{\text {******* }}$ & $137.21^{* * * * *}$ & $33.78^{* * * * * *}$ & $7.18^{* * *}$ & $10.87^{* * *}$ & 3.23 \\
\hline In words & 2.62 & 2.79 & 2.87 & 3.04 & $15.40^{* * * * * *}$ & $7.23^{* *}$ & 3.18 & 0.35 & 1.24 & 0.00 \\
\hline Story & 4.07 & 4.46 & 5.02 & 4.83 & $44.21^{* * * * * *}$ & $14.15^{* * * *}$ & 2.65 & 1.28 & 2.22 & 0.47 \\
\hline Pieces & 3.94 & 3.66 & 3.32 & 3.48 & $16.72^{\text {********* }}$ & 3.34 & 1.48 & 0.57 & 0.18 & 0.16 \\
\hline Life story & 2.57 & 4.97 & 5.01 & 5.03 & $413.35^{\text {****** }}$ & 0.25 & 0.01 & 0.58 & $4.95^{*}$ & $10.84^{* * *}$ \\
\hline Rehearsal & 3.29 & 4.11 & 4.50 & 4.57 & $135.70^{\text {********* }}$ & $20.67^{\text {******** }}$ & 2.03 & 1.44 & 0.61 & $6.73^{*}$ \\
\hline Involuntary & 2.67 & 2.97 & 3.44 & 3.78 & $97.85^{\text {***** }}$ & $62.34^{* * * * *}$ & $6.90^{* *}$ & $19.74^{* * * * *}$ & $11.77^{\text {***** }}$ & $11.80^{* * * *}$ \\
\hline Specific & 0.70 & 0.71 & 0.73 & 0.77 & $5.43^{*}$ & 3.10 & 0.97 & 0.02 & 0.61 & 0.09 \\
\hline Merged & 0.31 & 0.43 & 0.50 & 0.54 & $14.88^{* * * * *}$ & $6.65^{*}$ & 0.01 & 0.18 & 0.05 & 0.23 \\
\hline Age of memory & 4.07 & 4.31 & 2.53 & 3.82 & 1.10 & $4.50^{*}$ & $31.77^{* * * * *}$ & 0.09 & 0.64 & 1.25 \\
\hline
\end{tabular}

Note. For all variables, $F(1,113)$, except merged, which has $F(1,52), F(1,45)$, and $F(1,38)$ for word-cued, important, and positive comparisons, respectively. For the means of the three-way interaction of high versus low PCL group by negative versus another memory type, see Tables 3 and 4 . The age of memory variable is measured in years. PCL $=$ Posttraumatic Stress Disorder Check List.

${ }^{*} p<.05 .{ }^{* * *} p<.01 .^{* * * *} p<.001{ }^{* * * * *} p<.0001$.

expense of memory for peripheral details (Berntsen, 2002; Berntsen \& Rubin, 2006a; Christianson, 1992; Rubin et al., in press; Talarico, Berntsen, \& Rubin, in press). The lower rating for sensory variables is consistent with earlier studies showing reduced sensory details for emotionally negative relative to positive memories (Fredrickson, 2001; Fredrickson \& Branigan, 2005). For all three event comparisons, negative events have higher ratings on intensity and reaction and, of course, a lower rating on valence. When the negative events are compared with positive events, the differences with intensity and reaction are smaller but do not disappear. Thus, some of the other differences between the three most positive and three most negative events may be due to differences in intensity as well as valence. For the comparisons with word-cued and important events, for which there are large differences in both the valence and intensity of the memory ratings, there are also statistically significant differences in reliving, belief, hear, in words, story, rehearsal, and involuntary. Compared with the memories for the most important events, the word-cued memories are not specifically chosen to be part of the participants' life stories, and this may account for the differences in these two comparison memories on ratings related to rehearsal and to the narrative structure of the memories (i.e., story, pieces, and life story). Overall, the results are consistent with the basic mechanisms view that traumatic memories are coherent and often have higher ratings of key properties of autobiographical memory and contrary to the special mechanisms view that conscious and voluntary access to such memories are impaired relative to other autobiographical memories. Of special note are the higher values of memories for the three most negative events for the belief and story variables, which directly contradict the special mechanisms idea of fragmentation.

Table 5 shows the interactions of PCL group and the comparison events. Means supporting these ANOVAs are shown in Tables 3 and 4. Reaction and life story appeared in two comparisons, and involuntary appeared in all three. The interactions of these three variables are consistent with what we know about PTSD symptom severity in general. A physiological reaction to a negative memory and negative involuntary (i.e., intrusive) memories are PTSD symptoms, and a physiological reaction noted a day after a negative event predicts PTSD symptom severity much later (Talarico \& Rubin, 2003, 2007). Rating negative as opposed to other events as being part of the life story is the core of the CES measure discussed earlier, and this interaction is consistent with the basic mechanisms view, according to which the high PCL group should consider their most traumatic memories more central to their life story and identity than other autobiographical memories and more so than would the low PCL group. Several interactions appeared only once, and these appeared in the valence comparison with the most positive memories: field, intensity, and rehearsal. These interactions may be particular to this valence comparison, although intensity and rehearsal are similar to the reaction and involuntary variables that appeared in the other comparisons.

\section{Summary and Discussion of Study 1}

The main results are as follows. First, participants with high levels of PTSD symptoms had markedly higher scores on Neuroticism, slightly higher scores on Openness, and lower scores on 
Extraversion and Conscientiousness as compared with participants with low levels of PTSD symptoms. Second, for participants with high, compared with low, levels of PTSD symptoms, all types of memories had greater emotional intensity, more availability, and more relevance to life stories. The effects were linear over the level of PTSD symptoms, including participants whose PTSD severity scores were below the cutoff for having PTSD. Thus, in this sample, it is unlikely that an event was the only cause of the correlations between memories with greater emotional intensity, more availability, and more relevance to life stories and PTSD symptom severity. Rather, it is likely that participants who tend to experience all memories with greater emotional intensity and more relevance to their life stories also have greater PTSD symptom severity.

Third, participants' three most negative memories, compared with their 15 word-cued and 7 most important memories, have greater emotional intensity, availability, narrative coherence, recollection, and belief in their accuracy. This contradicts the special mechanisms view that voluntary access to traumatic memories is impaired and the related idea that such memories should be more fragmented. The findings generally support the basic mechanisms view. Moreover, by showing that people high in PTSD symptom severity react with more intense emotion in response to all four types of memories, and not just in response to the negative ones, the findings suggest that a general tendency to react with stronger emotion may be an important predisposing factor for the development of PTSD. It is likely that people who react with stronger emotion also develop more persistent and salient memories of the traumatic event because of enhanced encoding and rehearsal. In addition they are likely to react with more affect at the time of recall. These additive effects may explain symptoms of PTSD with no reference to trauma-specific mechanisms, consistent with the basic mechanisms view.

A limitation of Study 1 in relation to clarifying key issues of PTSD is that it provided data only on autobiographical memories retrieved in a voluntary fashion. As illustrated in Figure 1, a comprehensive study of memory in PTSD should also study involuntary (nonstrategic) memories for traumatic and nontraumatic autobiographical events. Study 2 was designed to meet this requirement.

\section{Study 2: Involuntary Memories}

\section{Method}

\section{Participants}

All 115 participants from Study 1 were invited to participate; 89 (40 in the low and 49 in the high PCL group) did and received $\$ 50$ each. Of these participants, 81 recorded 7 or more involuntary memories in the course of the week ( 35 in the low and 46 in the high PCL group), and we restrict our analyses to this group to obtain stable measures, except for our measure of number of involuntary memories, which is based on all 89 participants.

\section{Materials}

All participants were given a personal data assistant (PDA; Zire21, Palm, Inc., Sunnyvale, CA) to use for the week of data collection. The PDA was locked into a program that presented a modified form of the AMQ used in Study 1 (Entryware V5.0, Techneos Systems, Inc., Vancouver, British Columbia, Canada). The questions were shortened to fit easily onto the screen of the PDA. The dating of the memory was simplified to the following 7-point scale: This event occurred within the last (1) day, (2) week, (3) month, (4) year, (5) 5 years, (6) 10 years, or (7) longer. Three questions, shown in Table 1, were added to those used in Study 1 to probe issues directly related to the involuntary memories: Did the memory change the participant's mood, what cued it, and did it relate to the trauma? All responses were recorded on the PDA, which noted when they were made.

\section{Procedure}

Participants were recruited at the last session of Study 1 . They were read and given written instructions that included the following:

\begin{abstract}
Involuntary memories are memories about events in your personal past that come to you without your intention. Involuntary autobiographical memories can be cued by something in the environment or by a thought or by something you cannot identify. The key thing is that you cannot have been trying to recall the memory at the time. We are going to ask you to carry a PDA with you whenever you can for a week so that you can answer questions about involuntary autobiographical memories that you may experience as they occur. The questions you will answer are similar to those you answered on the previous questionnaires .... For each involuntary memory we will ask you to also record a voluntary autobiographical memory so we can look at similarities and differences in involuntary autobiographical memories (that come to you without your intention) versus voluntary autobiographical memories (memories you intentionally retrieved) .... To prevent this study from becoming a burden to you if you have lots of involuntary memories, after four involuntary memories in 1 day, the PDA will just record that you had an involuntary memory and not have you fill out any other questions .... In order to get a sample of voluntary memories of events that occurred from a similar time period, we ask you to record by hand on the pad attached to the PDA, the time period that the event occurred .... At a time that is convenient to you later that day, or if it is late in the day the next day, we ask you to look at the list, think about a voluntary memory of an event that occurred in about the same time period and answer questions about it (on the PDA).... If you miss recording an involuntary autobiographical memory because you cannot record it at the time, please do not go back and record it later .... Please start the week at midnight tonight. Please end it at midnight 1 week from today.
\end{abstract}

\section{Results}

Table 6 shows the means for the involuntary and voluntary memories in the high and low PCL group. First, compared with the low PCL group, the high PCL group had more trauma-related memories and more emotionally negative and intense memories, and their memories were accompanied by more reaction and mood change and were seen as more central to the life story. These effects largely replicate findings in Study 1. Second, the effects of PCL group were uninfluenced by whether recall was voluntary or involuntary. As shown in Table 6, involuntary and voluntary recall followed the same pattern of results regardless of level of PTSD symptom severity; there were main effects of PCL group and of voluntary versus involuntary memories, but there were no significant interactions. This finding is consistent with predictions derived from the basic mechanisms view but counter to the special mechanisms view in that involuntary recall 
Table 6

Comparison of Involuntary and Voluntary Memories From Study 2

\begin{tabular}{|c|c|c|c|c|c|c|c|c|c|}
\hline \multirow[b]{3}{*}{ Variable } & \multicolumn{3}{|c|}{ Involuntary } & \multicolumn{3}{|c|}{ Voluntary } & \multirow{3}{*}{$\begin{array}{l}\text { PCL group, } \\
F(1,79)\end{array}$} & \multirow{3}{*}{$\begin{array}{c}\text { Voluntary-involuntary, } \\
\qquad F(1,79)\end{array}$} & \multirow{3}{*}{$\begin{array}{c}\text { Interaction } \\
F(1,79)\end{array}$} \\
\hline & \multicolumn{2}{|c|}{ PCL group } & \multirow[b]{2}{*}{$r(79)$} & \multicolumn{2}{|c|}{ PCL group } & \multirow[b]{2}{*}{$r(79)$} & & & \\
\hline & Low $(M)$ & High $(M)$ & & Low $(M)$ & $\operatorname{High}(M)$ & & & & \\
\hline Reliving & 3.88 & 4.16 & .16 & 3.82 & 4.13 & .08 & 1.72 & 0.27 & 0.02 \\
\hline Belief & 5.32 & 5.19 & .06 & 5.36 & 5.16 & .01 & 0.72 & 0.02 & 0.24 \\
\hline See & 5.32 & 5.45 & .14 & 5.38 & 5.57 & .13 & 0.86 & 1.55 & 0.13 \\
\hline Field & 4.89 & 4.74 & -.08 & 4.70 & 4.53 & -.13 & 0.57 & $5.20^{*}$ & 0.00 \\
\hline Setting & 5.42 & 5.43 & .06 & 5.54 & 5.69 & .14 & 0.20 & $6.64^{*}$ & 0.89 \\
\hline Hear & 3.96 & 4.31 & .18 & 3.74 & 4.10 & .17 & 2.25 & 3.82 & 0.01 \\
\hline Smell & 1.82 & 1.96 & .07 & 1.95 & 2.04 & .04 & 0.37 & 2.28 & 0.01 \\
\hline Valence & 0.64 & 0.11 & $-.38^{* * * *}$ & 0.61 & 0.35 & -.17 & $10.24^{* *}$ & 1.86 & 0.01 \\
\hline Intensity & 2.80 & 3.29 & .19 & 2.64 & 3.23 & .14 & $7.32^{* * *}$ & 1.72 & 0.26 \\
\hline Reaction & 2.53 & 2.91 & .16 & 2.24 & 2.69 & .10 & $4.70^{*}$ & $10.10^{* *}$ & 0.19 \\
\hline Mood change & 3.11 & 3.72 & $.24^{*}$ & 2.69 & 3.28 & .14 & $9.17^{* * *}$ & $30.46^{* * * * *}$ & 0.02 \\
\hline In words & 2.67 & 2.83 & .07 & 2.60 & 2.77 & .07 & 0.34 & 0.70 & 0.01 \\
\hline Story & 4.22 & 4.39 & .12 & 4.52 & 4.66 & .05 & 0.48 & $8.81^{* *}$ & 0.02 \\
\hline Pieces & 3.68 & 3.56 & -.11 & 3.53 & 3.38 & -.06 & 0.35 & 3.48 & 0.04 \\
\hline Life story & 1.79 & 2.37 & $.41^{* * * *}$ & 2.14 & 2.50 & .18 & $7.79^{* * *}$ & $9.92^{* * *}$ & 1.99 \\
\hline Rehearsal & 3.20 & 3.20 & .02 & 3.38 & 3.41 & -.07 & 0.01 & $4.72^{*}$ & 0.02 \\
\hline Involuntary & 2.84 & 3.18 & $.24^{*}$ & 2.71 & 2.91 & .04 & 3.70 & 3.78 & 0.42 \\
\hline Specific & 0.75 & 0.72 & -.09 & 0.83 & 0.82 & .01 & 0.42 & $20.02^{* * * * *}$ & 0.69 \\
\hline Merged $^{\mathrm{a}}$ & 0.29 & 0.18 & -.19 & 0.29 & 0.30 & .06 & 0.68 & $7.08^{*}$ & 3.16 \\
\hline Age of memory & 3.72 & 3.66 & -.01 & 3.69 & 3.68 & .05 & 0.05 & 0.01 & 0.95 \\
\hline Trauma related & 0.08 & 0.18 & $.31^{* * *}$ & .09 & .18 & $.26^{*}$ & $10.95^{* * *}$ & 0.01 & 0.14 \\
\hline
\end{tabular}

a The degrees of freedom for this variable are 1 and 55 .

${ }^{*} p<.05 .^{* * *} p<.01 .^{* * * *} p<.001 .^{* * * * *} p<.0001$.

did not yield more frequent access to trauma-related memories than did voluntary recall.

Third, a number of differences were observed between involuntary memories and voluntary memories. The involuntary memories were accompanied by more reaction and mood change and involved more field perspective but had less information on setting, came less as a coherent story, were rehearsed less voluntarily, were less relevant to the life story, and were less specific (i.e., less often occurred within a single day) than the voluntary counterparts. From a basic mechanisms view, most of these differences are explained in terms of dissimilar retrieval processes (associative and bottom up versus strategic and top down) operating on the same autobiographical memory system. In particular, the associative and uncontrolled retrieval process that characterizes involuntary memories leaves less opportunity for emotion regulation (Gross, 2001), resulting in stronger emotional reaction at recall. The involuntary retrieval process is also less suitable for accessing memories indexed in terms of the life narrative or other types of narrative information as compared with the controlled, schema, and narrative based search strategies characterizing voluntary recall. Support for the idea that involuntary and voluntary processes retrieve different memories even though they are both affected equally by PTSD symptom severity comes from the retrospective availability measures in Table 6 . Voluntary rehearsal is judged to have occurred more frequently to voluntary memories, whereas prior involuntary occurrences are judged to have occurred more frequently to involuntary memories. To test this concept more formally, we did a Voluntary Versus Involuntary Retrieval $\times$ Prior Voluntary Versus Involuntary Rehearsals (i.e., rehearsal vs. involuntary) $\times$ PCL Group ANOVA. We found three significant ef- fects: a main effect caused by there being more reports of past voluntary rehearsal, $F(1,79)=41.57, p<.0001$; an interaction caused by the high PCL group increasing reports of past involuntary rehearsal more than voluntary rehearsal, $F(1,79)=4.49, p<$ .05 ; and the expected interaction, $F(1,79)=34.80, p<.0001$.

In Study 1, participants rated memories for their three most negative events. In Study 2, because we could not specify the type of involuntary memory we would like to have recorded, we had participants indicate on the PDA whether the memory they recorded was unrelated to, related to, or about one of their three most negative events. Only $3 \%$ of the memories were reported to be about one of the three most negative events, compared with $14 \%$ reported to be about or related to these events (see Table 6). We therefore used the proportion of involuntary and voluntary memories that each participant indicated was about or related to one of their three most stressful memories in all analyses. The ANOVAs in Table 7 are based on the 42 participants who recorded both an involuntary and a voluntary memory about or related to one of their three most negative events: 15 from the low PLC group and 27 from the high PCL group. Because there are more participants available for the ANOVAs in Table 6, here we report only main effects and interactions involving the traumarelated factor. The main effects shown in Table 7 are similar to the ones shown earlier for the voluntary memories comparisons of wordcued and important memories with the three most negative events of Study 1 . That is, both trauma-related voluntary and involuntary memories involved more negative valence, intensity, reaction, mood change, life story relevance, and rehearsal as compared with memories that were unrelated to the trauma. Thus, trauma-related memories appeared to be more available than memories with no reference to the trauma. This finding is contrary to the special mechanisms view that 
Table 7

Comparison of Trauma-Related and Nontrauma-Related Memories From Study 2

\begin{tabular}{|c|c|c|c|c|c|c|}
\hline \multirow[b]{3}{*}{ Variable } & & & \multicolumn{4}{|c|}{ Trauma related: Analysis of variance, $F(1,40)$} \\
\hline & \multicolumn{2}{|c|}{$M$} & \multirow[b]{2}{*}{ Main effect } & \multicolumn{3}{|c|}{ Interaction } \\
\hline & No & Yes & & PCL group & Involuntary & Three way \\
\hline Reliving & 3.91 & 4.19 & $4.40^{*}$ & 0.41 & 0.33 & 3.40 \\
\hline Belief & 5.24 & 5.02 & 2.32 & 0.90 & 0.78 & 0.58 \\
\hline See & 5.42 & 5.42 & 0.01 & 0.08 & 1.10 & 0.18 \\
\hline Field & 4.66 & 4.47 & 1.11 & 0.01 & 0.01 & 3.58 \\
\hline Setting & 5.54 & 5.42 & 0.18 & 4.02 & 3.55 & 0.01 \\
\hline Hear & 4.21 & 4.40 & 2.08 & 0.02 & 2.37 & 0.68 \\
\hline Smell & 2.05 & 2.39 & 2.59 & 0.40 & 0.01 & 3.80 \\
\hline Valence & $0.62-0.93$ & $64.18^{* * * * *}$ & 0.01 & $4.36^{*}$ & $7.08^{*}$ & \\
\hline Intensity & 2.98 & 4.15 & $50.76^{* * * * * *}$ & 0.07 & 0.14 & 0.13 \\
\hline Reaction & 2.63 & 3.29 & $13.99^{* * * *}$ & 0.01 & 1.02 & 0.12 \\
\hline Mood change & 3.26 & 4.19 & $46.48^{* * * * * *}$ & 0.11 & 0.00 & 0.01 \\
\hline In words & 2.78 & 3.00 & $5.91^{*}$ & 0.63 & 0.00 & 1.73 \\
\hline Story & 4.46 & 4.45 & 0.13 & 2.39 & 1.90 & 0.08 \\
\hline Pieces & 3.44 & 3.78 & 2.27 & 2.79 & 0.02 & 0.21 \\
\hline Life story & 2.16 & 3.84 & $71.19^{* * * * * *}$ & 2.57 & 0.00 & 0.03 \\
\hline Rehearsal & 3.27 & 4.32 & $32.66^{* * * * * *}$ & 0.37 & 0.26 & 0.15 \\
\hline Involuntary & 2.83 & 4.08 & $27.61^{* * * * * *}$ & 1.32 & 0.09 & 0.18 \\
\hline Specific & 0.78 & 0.72 & 1.66 & 0.04 & 1.13 & 0.52 \\
\hline Merged $^{\text {a }}$ & 0.21 & 0.31 & 0.88 & 0.10 & 0.12 & 0.18 \\
\hline Age of memory & 3.66 & 4.27 & $11.84^{* *}$ & $8.30^{* * *}$ & 0.44 & 2.36 \\
\hline
\end{tabular}

Note. Only the effects involving being related are shown, as other effects are shown with more participants earlier. PCL $=$ Posttraumatic Stress Disorder Check List.

${ }^{\mathrm{a}}$ The degrees of freedom for this variable are 1 and $11 .{ }^{\mathrm{b}}$ This variable is from the 7-point rating scale described in the Procedure section of Study 2. * $p<.05$. $^{* * *} p<.01$. $^{* * * *} p<.001$. $^{* * * * * *} p<.0001$.

traumatic experiences are unavailable to voluntary recall and disintegrated in memory.

There were few interactions with the trauma-related factor, which also contradicts the special mechanisms view, according to which the trauma-related factor should show differential effects for involuntary versus voluntary recall and of high versus low levels of PTSD symptom severity. For age of memory, the two-way interaction with PCL group was caused by the high PCL group having older memories for trauma-related events and younger memories for nontrauma-related events compared with the low PCL group. For valence, there was a two-way interaction with voluntary versus involuntary memories caused by the valence being more positive for the voluntary memories not related to trauma compared with the voluntary memories related to trauma. The three-way interaction is caused by the high PCL group having higher valence for the voluntary memories and the low PCL group having lower valence for the voluntary memories but only for the trauma-related memories.

\section{Summary and Discussion of Study 2}

Several differences were found between the high versus low PCL group. These differences were largely the same as the ones observed in Study 1. The high PCL group had more emotional reactions to their memories and considered them as more central to their life story than did the low PCL group. These effects were unaffected by whether recall was involuntary or voluntary, contrary to the special mechanisms view but consistent with predictions derived from the basic mechanisms view.
Several differences were observed between involuntary versus voluntary recall. Except for the finding that involuntary memories were less specific, these findings replicated and extended previous work on involuntary autobiographical memories and are consistent with the idea that differences in the characteristics of the two types of memory can be explained in terms of different retrieval mechanisms operating on the same memory system (Berntsen, in press). The difference in specificity may be caused by differences in the instructions and in the specificity measures used. Unlike previous studies, the participants were asked to record memories of only specific events, to recall comparison voluntary memories from the same time period as each involuntary memory rather than to a word cue, and to report three categories of specificity rather than two (following J. M. G. Williams, 1996).

Because involuntary memories arise associatively with no preceding search description, they allow for less emotion regulation and thus more emotional reaction and mood change than the voluntary memories. The lack of a search also means that involuntary memories are less likely to involve one of the most common forms of search, narrative organization (Conway, 2005; Conway \& Pleydell-Pearce, 2000; Rubin, 2006), and thus are less likely to be central to the person's life story. These characteristics apply to involuntary memories in general but can explain some of the key characteristics of involuntary memories of traumatic events both in the description and diagnosis of PTSD. As predicted by the basic mechanisms view, involuntary recall did not access trauma-related memories more frequently than did voluntary recall. 
Study 2 also showed that trauma-related memories differed systematically from memories with no relation to the trauma, especially with regard to emotional content and participants' emotional reaction at the time of recall. Again these differences were not modified by voluntary versus involuntary retrieval, consistent with the basic mechanisms view.

The similarities observed between the involuntary and voluntary memory conditions are unlikely to reflect carry-over effects. First, although the voluntary memory was from the same time period as the involuntary memory, it was recalled after a substantial delay, either later the same day or the day after, also rendering carryover effects unlikely. Second, although the two types of memories did not differ in the ways predicted by the special mechanisms theories, a number of other differences were observed, replicating and extending findings from earlier diary studies with different recording procedures (e.g., Berntsen \& Hall, 2004).

In short, the findings support the basic mechanisms view and lend further support to the idea that a tendency to react with intense affect may be an important predisposing factor for PTSD. To pursue this possibility as well as the claim that no special mechanisms are needed to account for the present findings, we conducted correlational analyses across Studies 1 and 2 .

\section{Correlational Analyses Across Studies 1 and 2 \\ Correlations of $A M Q$ and Individual Differences Measures}

The earlier analyses showed that AMQ variables related to emotional intensity (i.e., intensity and reaction), availability (i.e., rehearsal and involuntary), and life story increased with PTSD symptom severity. Here we investigated whether other individual differences variables had the same or different effects on these and other AMQ variables. Table 8 provides correlations with the individual differences measure including the five NEO domains, the number of involuntary memories, and the proportion of trauma-related voluntary and involuntary memories that each individual produced in Study 2. Correlations with the PCL, which were discussed earlier, are included for completeness as well as to allow comparison with the DTS. Although many of the correlations could not be predicted, they are theoretically reasonable and consistent with earlier results in that they tended to involve intensity, availability, and life story measures. There were no good predictors of the number of involuntary memories reported. However, as predicted by the basic mechanism view, frequency of memories with trauma-related content correlated positively with level of PTSD symptoms for both voluntary and involuntary memories.

\section{Correlations of the A, B, C, and D Symptoms of PTSD Tests With Other Measures}

To have PTSD, a person must display B, C, and D symptoms caused by a particular kind of event (American Psychiatric Association, 2000) at least 1 month after the event that results in significant distress or impaired functioning. The event must be a trauma that meets the A criteria. That is, it must involve actual or threatened death, serious injury, or the threat to the physical integrity of self or others (the A1 criterion), and it must result in

Table 8

Correlations of Individual Differences Measures With $A M Q$ and Number of Involuntary Memories

\begin{tabular}{|c|c|c|c|c|c|c|c|c|c|c|}
\hline Variable & PCL & DTS & BDI & CES & DES & $\mathrm{N}$ & $\mathrm{E}$ & $\mathrm{O}$ & A & $\mathrm{C}$ \\
\hline Reliving & -.02 & -.05 & -.10 & -.06 & .13 & -.05 & .17 & .05 & .07 & $.22^{*}$ \\
\hline Belief & -.12 & $-.19^{*}$ & -.13 & .03 & -.09 & $-.21^{*}$ & $.28^{* * *}$ & .05 & .13 & $.28^{* *}$ \\
\hline See & -.03 & -.12 & -.13 & -.03 & .02 & -.13 & $.26^{* * *}$ & .17 & .18 & $.32^{* * * *}$ \\
\hline Field & -.11 & -.18 & -.17 & -.18 & .03 & -.08 & .04 & .05 & .09 & .09 \\
\hline Setting & -.04 & -.14 & -.13 & .00 & -.03 & -.12 & $.25^{* * *}$ & .15 & .17 & $.28^{* * *}$ \\
\hline Hear & $.21^{*}$ & .13 & .12 & .09 & $.19^{*}$ & .08 & $.19^{*}$ & .18 & .06 & .05 \\
\hline Smell & $.22^{*}$ & .15 & .16 & .17 & $.27^{* * *}$ & .13 & .00 & $.31^{* * * *}$ & .10 & -.11 \\
\hline Valence & -.12 & $-.22^{*}$ & $-.25^{* *}$ & $-.26^{* *}$ & -.04 & $-.22^{*}$ & $.40^{* * * * *}$ & .14 & .11 & .15 \\
\hline Intensity & $.37^{* * * * *}$ & $.29^{* * *}$ & .09 & $.22 *$ & $.31^{* * * *}$ & $.24^{*}$ & .08 & .10 & .08 & .01 \\
\hline Reaction & $.36^{* * * * *}$ & $.31^{* * * * *}$ & .14 & $.24^{*}$ & $.33^{* * * *}$ & .17 & .11 & -.01 & .10 & -.02 \\
\hline In words & .01 & .06 & -.02 & .11 & .09 & .03 & .00 & -.02 & .02 & .15 \\
\hline Story & -.02 & -.02 & -.07 & .03 & -.04 & -.07 & .13 & -.18 & .16 & $.27^{* * *}$ \\
\hline Pieces & .08 & .05 & .03 & .05 & .12 & .09 & -.13 & .16 & -.11 & -.18 \\
\hline Life story & $.28^{* * *}$ & $.19^{*}$ & .09 & $.19^{*}$ & $.25^{\text {** }}$ & $.19^{*}$ & .03 & .17 & .16 & .09 \\
\hline Rehearsal & $.22^{*}$ & $.22^{*}$ & .05 & $.21^{*}$ & .09 & .05 & $.19^{*}$ & $.25^{* *}$ & .10 & -.01 \\
\hline Involuntary & $.30^{* * *}$ & $.29^{* * *}$ & .08 & $.28^{* * *}$ & $.21^{*}$ & $.20^{*}$ & .11 & $.24^{* *}$ & .00 & -.07 \\
\hline Specific & -.14 & -.14 & -.06 & -.13 & $-.19^{*}$ & -.08 & .05 & $-.26^{* * *}$ & -.02 & .10 \\
\hline Merged & -.03 & -.02 & -.12 & .07 & -.01 & -.03 & -.04 & -.06 & .00 & -.01 \\
\hline Age of memory & .18 & $.27^{* * *}$ & .14 & .13 & .07 & .11 & $-.20^{*}$ & -.09 & -.05 & -.07 \\
\hline No. involutary ${ }^{a}$ & -.07 & -.15 & -.07 & -.15 & -.05 & .00 & .15 & .16 & .02 & .09 \\
\hline \multicolumn{11}{|l|}{ Trauma related } \\
\hline Involuntary & $.31^{* * *}$ & $.25^{*}$ & $.23^{*}$ & .20 & .12 & $.22^{*}$ & -.07 & .07 & .13 & -.03 \\
\hline Voluntary & $.26^{*}$ & $.29^{* * *}$ & .14 & $.31^{* * *}$ & .18 & .21 & -.11 & -.10 & .10 & -.10 \\
\hline
\end{tabular}

Note. There are 115 observations for each correlation except No. involuntary, which has 89. AMQ = Autobiographical Memory Questionnaire; PCL = Posttraumatic Stress Disorder Check List; DTS = Davidson Trauma Scale; BDI = Beck Depression Inventory; CES = Centrality of Event Scale; DES = Dissociative Experiences Scale; $\mathrm{N}=$ Neuroticism; $\mathrm{E}=$ Extraversion; $\mathrm{O}=$ Openness; $\mathrm{A}=$ Agreeableness; $\mathrm{C}=\mathrm{Conscientiousness}$.

${ }^{a}$ No. involuntary is the number of involuntary memories produced by each participant.

${ }^{*} p<.05 .{ }^{* *} p<.01 .^{* * *} p<.001 .^{* * * * *} p<.0001$. 
Table 9

Correlations With A, B, C, and D Symptoms and A1 and A2 Subscales of PTSD Tests

\begin{tabular}{|c|c|c|c|c|c|c|}
\hline Variable & $\geq 1$ A trauma & No. of A1 events & No. of A2 emotions & $\mathrm{B}$, reexperience & $\mathrm{C}$, avoidance & $\mathrm{D}$, arousal \\
\hline \multicolumn{7}{|c|}{ AMQ ratings from all memories combined } \\
\hline Belief & -.05 & .02 & -.02 & -.14 & $-.22^{*}$ & -.10 \\
\hline Hear & .07 & .04 & .06 & .11 & .14 & $.18^{*}$ \\
\hline Smell & .07 & .12 & .09 & .10 & $.19^{*}$ & $.20^{*}$ \\
\hline Valence & .04 & .01 & -.06 & $-.19^{*}$ & -.16 & -.18 \\
\hline Intensity & .10 & .08 & .13 & $.34^{* * *}$ & $.28^{* * *}$ & $.27^{* * *}$ \\
\hline Reaction & .05 & .04 & -.01 & $.39^{* * * * * *}$ & $.29^{* * *}$ & $.24^{* * *}$ \\
\hline Life story & -.04 & .03 & .07 & $.19^{*}$ & $.21^{*}$ & $.19^{*}$ \\
\hline Rehearsal & .03 & .09 & -.08 & $.32^{* * *}$ & .16 & .16 \\
\hline Involuntary & -.01 & -.05 & .08 & $.35^{* * * *}$ & $.22^{*}$ & $.26^{* * *}$ \\
\hline Age of memory & .03 & .06 & .20 & .17 & $.27^{* * *}$ & $.21^{*}$ \\
\hline \multicolumn{7}{|c|}{ Life story from original 7 most important events } \\
\hline Valence & -.04 & -.04 & $-.23^{*}$ & $-.22^{*}$ & -.16 & $-.19^{*}$ \\
\hline Intensity & .16 & .15 & $.24^{*}$ & $.33^{* * *}$ & $.30^{* * *}$ & $.32^{* * * *}$ \\
\hline Reaction & .08 & .10 & .11 & $.37^{* * * * * *}$ & $.31^{* * * *}$ & $.29^{* * *}$ \\
\hline \multicolumn{7}{|l|}{ Standardized tests } \\
\hline PCL & .02 & -.02 & $.32^{* * * * *}$ & $.81^{* * * * * *}$ & $.86^{* * * * * *}$ & .82 ******* \\
\hline DTS & -.04 & -.06 & $.26^{* *}$ & $.86^{* * * * *}$ & $.91^{* * * * * *}$ & $.87^{* * * * * * * *}$ \\
\hline BDI & -.09 & -.05 & $.22^{*}$ & $.52^{* * * * *}$ & $.73^{* * * * * * *}$ & 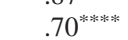 \\
\hline CES & .07 & .03 & $.42^{* * * * *}$ & $.49^{* * * * *}$ & $.56^{* * * * * *}$ & $.50^{* * * * * *}$ \\
\hline DES & .01 & .05 & $.24^{*}$ & $.57^{* * * * *}$ & $.62^{* * * * *}$ & $.61^{* * * * *}$ \\
\hline \multicolumn{7}{|l|}{ NEO domains } \\
\hline Neuroticism & -.06 & -.13 & $.27^{* * *}$ & $.48^{* * * * * *}$ & $.64^{* * * * * *}$ & $.58^{* * * * * * *}$ \\
\hline Extroversion & $.30^{\text {*** }}$ & $.23^{*}$ & -.03 & -.18 & $-.42^{* * * * *}$ & $-.28^{* *}$ \\
\hline Openness & .11 & .10 & .00 & $.22^{*}$ & .09 & $.20^{*}$ \\
\hline Conscientiousness & -.06 & -.04 & -.06 & $-.22^{*}$ & $-.37^{* * * * * *}$ & $-.44^{* * * * * * *}$ \\
\hline Gender & .01 & .06 & .13 & .07 & .03 & .02 \\
\hline No. involutary ${ }^{a}$ & -.04 & -.01 & -.11 & .01 & -.17 & -.15 \\
\hline \multicolumn{7}{|l|}{ Trauma Related } \\
\hline Involuntary & -.04 & -.12 & .06 & $.34^{* * *}$ & $.25^{*}$ & .18 \\
\hline Voluntary & -.08 & -.06 & .03 & $.32^{* * *}$ & $.33^{* * *}$ & .13 \\
\hline
\end{tabular}

Note. Only variables that have a correlation that is significant at the $p<.05$ level and gender and No. involuntary are shown. For gender, male $=0$, female $=1$. There are 113 degrees of freedom for all variables except the following: No. involuntary, which has 87 , and the two trauma-related variables, which have 79. PTSD = posttraumatic stress disorder; PCL = PTSD Check List; DTS = Davidson Trauma Scale; BDI = Beck Depression Inventory; CES = Centrality of Event Scale; DES = Dissociative Experiences Scale; NEO = NEO Personality Inventory.

${ }^{\mathrm{a}}$ No. involuntary is the number of involuntary memories produced by each participant.

${ }^{*} p<.05 .{ }^{* * *} p<.01$. $^{* * * *} p<.001 .{ }^{* * * * *} p<.0001$.

the person feeling intense fear, horror, or helplessness (the A2 criterion). Published work tends not to examine the A, B, C, and D symptoms separately, but we do because they are conceptually different in ways that are relevant to the basic mechanisms view, and they could have distinct relations to the individual differences and memory properties we measured.

Table 9 presents the correlations of the AMQ and individual differences measures with the A, B, C, and D symptoms of PTSD. Here and in other work we have done with student populations (Berntsen \& Rubin, 2006c, 2007), the A criterion is an outlier and does not correlate with other measures including the two PTSD tests, which measure the $17 \mathrm{~B}, \mathrm{C}$, and $\mathrm{D}$ symptoms. The only variable that correlates with whether our participants did or did not have an event that met the A criterion is the Extraversion domain of the NEO. If we examine the correlations of the six facets of the Extraversion domain with whether our participants had at least one A criterion event, the highest two correlations are .27 with E5, excitement seeking, and .24 with E4, activity. Both correlations have clear face validity in that high-activity, excitement-seeking people are more likely to experience traumas. To meet the A criterion, both the A1 and the A2 criteria have to be met. The measures of the percentage of the three negative memories that are reported as A1 events and that are reported as having A2 emotions provide clarification on which variables contribute to each component. The only variable in Table 9 to correlate with percentage of very stressful events reported as being A1 is the Extraversion domain of the NEO. In contrast, the individual differences measures of Neuroticism and the PCL, DTS, BDI, CES, and DES all correlate with the percentage of events that have A2 emotions, as do valence and intensity averaged over the participants' most important seven events. Thus, reporting an event that involves the $\mathrm{A} 1$ criterion and having the $\mathrm{A} 2$ emotions are related to different measures. In contrast to the A criterion, the B, C, and D criteria are more similar in their patterns of correlations. Some scales such as the CES and DES correlate equally with the B, C, and D symptoms. Others, such as the AMQ measures of emotional intensity and availability correlate most highly with the B symptoms, whereas other measures, such as the BDI, NEO Neuroticism, and NEO Conscientiousness, appear to correlate more highly with the $\mathrm{C}$ and $\mathrm{D}$ symptoms. Because there is little empirical work that tries to separate the three kinds of symptoms, the comparisons made here are tentative and require replication, especially replication 
with a clinical sample. They do, however, point to interesting possibilities to understand the dynamics of PTSD.

\section{Study 3: Affect Intensity}

The results of the previous two studies, including the correlational analyses just presented, suggest that people who feel emotions more intensely, even for word-cued memories, report higher levels of PTSD symptoms. The closest concept we could find for increased intensity of emotions over a range of stimuli is the concept of affect intensity (for reviews, see Larsen, in press; Larsen \& Diener, 1987). Affect intensity is a stable attribute, or disposition, that indicates how strongly people experience both their positive and negative emotions. It affects how intensely people react to hypothetical and actual life events (Larsen, Diener, $\&$ Emmons, 1986). We therefore wanted to measure affect intensity using the 40-item Affect Intensity Measure (AIM) developed to index it (Larsen \& Diener, 1987). This scale was formed by selecting items from among those thought to have high face validity with the concept of affect intensity.

Psychometric studies of the AIM find that the scale may not include a single concept of affect intensity, but four factors: Positive Affectivity, Negative Intensity, Serenity, and Negative Reactivity (Weinfurt, Bryant, \& Yarnold, 1994; D. G. Williams, 1989). Conceptually, the items on the Negative Intensity factor fit best with our findings in that they would help to account for the observations from Study 1 that intensity correlated with the PCL more highly in the three most negative memories as opposed to in the three most positive memories. Moreover, Lynch, Robins, Morse, and Krause (2001) found that four items from the Negative Intensity factor had correlations of .46 with a measure of thought suppression (the White Bear Suppression Inventory; Wegner \& Zanakos, 1994) and .28 with the BDI in a patient sample and .45 and .42 , respectively, in an undergraduate sample. On the basis of these and other measures, Lynch et al. formulated a model in which Negative Intensity leads to emotion inhibition, which leads to psychological distress. Although they did not apply this model directly to PTSD, conceptually it would fit quite well. We were therefore interested to see whether the entire AIM scale of affect intensity or the Negative Intensity factor would correlate more highly with PTSD symptom severity. A second goal was to ensure that our findings were not overly inflated or otherwise biased by performing correlations on a sample that had selected people on the basis of extreme scores on the PCL. We therefore tested a new sample of undergraduates on the AIM and on three tests we had used earlier - the BDI, CES, and PCL—so that we could compare those correlations with the ones obtained in Study 1.

\section{Method}

As part of a Web-based selection procedure used to identify participants for other studies, we obtained a sample of 533 Duke undergraduates who completed the AIM, BDI, CES, PCL, and the A1 and A2 PTSD criteria (318 women, 215 men; mean age = $19.33, S D=1.38$ ).

\section{Results}

\section{Analysis of the AIM}

We analyzed our AIM data using the same statistical procedure as D. G. Williams (1989) to make a direct comparison easier. In particular, following D. G. Williams (1989), we used a principal components factor analysis with a varimax rotation with a four-factor solution. We had seven factors with eigenvalues greater than $1(9.61,5.17,3.12,1.81,1.41,1.34$, and 1.20 ), which accounted for $59 \%$ of the variance. Our four factors were very close to those of Williams, so we use his names for them: Negative Intensity, Negative Reactivity, Positive Affectivity, and Serenity. Here we concentrate on the Negative Intensity factor not only because conceptually it seemed most related to our results but also because, as we show next, items on it correlate most highly with the PCL. Following D. G. Williams (1989), we also included items on factors if they had loadings greater than or equal to .40 . Using the .40 cutoff, the lowest loading included for Negative Intensity was .49 and the highest loading excluded was .34 , so there was a clear division between items that were considered as part of this factor and those that were not. Our 9 Negative Intensity items include all of the 8 items Williams included in his Negative Intensity factor, and they include all but 1 of the 10 items Weinfurt et al. (1994) included in their Negative Intensity factor, so there is good agreement with earlier studies. It also includes the 4 items used by Lynch et al. (2001). In addition, two factor-analytic studies compared Weinfurt et al.'s fourfactor solution with their own preferred three-factor solutions, which were based on a subset of 27 of the 40 AIM items chosen on their face validity to a more restricted conceptual model than Larsen and Diener (1987) originally outlined (Bryant, Yarnold, \& Grimm, 1996; Simonsson-Sarnecki, Lundh, \& Törestad, 2000). In these studies, for the reduced sample of 27 items, the two positive factors collapsed into one factor, but the Negative Intensity factor remained. Moreover, for all 40 items, Weinfurt et al.'s four-factor solution provided about as good a fit as did their preferred solution for their subset of 27 items.

Using the numbers of the items on the AIM, the nine items on our Negative Intensity factor are as follows:

6. My emotions tend to be more intense than those of most people.

15. My friends might say I'm emotional.

19. "Calm and cool" could easily describe me (reverse scored).

26. I can remain calm even on the most trying days (reverse scored).

28. When I get angry, it's easy for me to still be rational and not overreact (reverse scored).

30. When I do feel anxiety, it is normally very strong.

31. My negative moods are mild in intensity (reverse scored).

34. My friends would probably say I'm a tense or "highstrung" person.

39. When I am nervous, I get shaky all over. 
These items capture a major component of the original concept of affect intensity, in general, and also have items that apply only to negative emotions. This includes emotional intensity in general (Items 6 and 31) and emotional intensity for anger and anxiety in particular (Items 28 and 30), the general daily level of emotional arousal (Items 15, 19, and 26), and tension and visceral reactions (Items 34 and 39). As Weinfurt et al. (1994) noted, this collection of items is conceptually similar to the negative affectivity trait of Watson and Clark (1984). The factor's emphasis on intensity and on visceral reactions is consistent with the findings of Studies 1 and 2, and its emphasis on anxiety and anger is consistent with PTSD being an anxiety disorder and on the literature on anger being an important emotion in PTSD (see Rubin et al., in press, for a review).

The 8 items of the 40-item AIM that correlated most highly with the PCL all came from the 9 items of the Negative Intensity factor. Their correlations ranged from .17 to .38 . The remaining item on the Negative Intensity factor had a correlation of .16. Thus, the items that make up the Negative Intensity factor correlate highly with the PCL; the remaining items of the AIM did not correlate as well.

\section{Correlation Among the Variables}

We summed the scores on the items in each factor to produce our measures of Negative Intensity, Positive Affectivity, Serenity, and Negative Reactivity. Table 10 shows how the A1, A2, A, B, C, and D components of PTSD correlate with the BDI, CES, and the four factors of the AIM. As expected from the discussion of the individual items that loaded on the Negative Intensity factor, Negative Intensity had much higher correlations with the PCL overall and with its B, C, and D symptoms than did the other three AIM factors and the AIM as a whole. As with the other individual differences tests, the A1 produced smaller correlations than the A2. Of note, the Serenity factor had no correlations larger in magnitude than .04 with any of the PTSD criteria or symptoms. When compared with the Negative Intensity correlations, this argues strongly for using individual factors of the AIM, instead of combining all items into one scale, when using the test to try to understand PTSD.

Figure 4 plots Negative Intensity, the BDI, and the CES as a function of the PCL scores to ensure that the effects are linear and

Table 10

Correlations Among Measures

\begin{tabular}{lrrrrrr}
\hline \multicolumn{1}{c}{ Measure } & PCL & A1 & A2 & B & C & D \\
\hline BDI & .63 & -.04 & .21 & .51 & .60 & .57 \\
CES & .55 & .13 & .32 & .53 & .53 & .39 \\
AIM & .25 & .03 & .18 & .29 & .17 & .21 \\
Negative Intensity & .42 & .01 & .20 & .42 & .34 & .38 \\
Negative Reactivity & .12 & .08 & .13 & .16 & .09 & .09 \\
Positive Affectivity & .12 & .02 & .14 & .15 & .08 & .08 \\
Serenity & .01 & .00 & -.02 & .04 & -.04 & .02 \\
\hline
\end{tabular}

Note. All correlations are based on 533 observations; therefore, correlations greater than or equal to .09 have $p<.05$, and correlations greater than or equal to .17 have $p<.0001$. PCL $=$ Posttraumatic Stress Disorder Check List; BDI = Beck Depression Inventory; CES = Centrality of Event Scale; AIM $=$ Affect Intensity Measure.

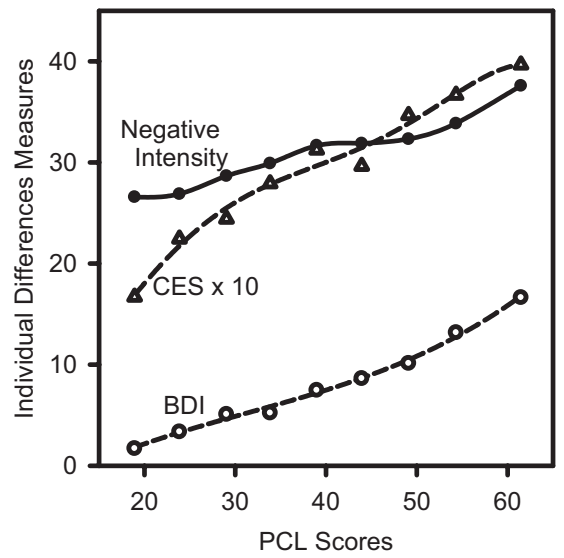

Figure 4. The increase in scores of Negative Intensity, the Beck Depression Inventory (BDI), and Centrality of Events Scale (CES), as a function of posttraumatic stress disorder (PTSD) symptom severity as measured by the PTSD Check List (PCL) from Study 3.

to see whether the correlations hold for people with scores above and below the PCL statistical cutoff for PTSD of 44. As for Figures 2 and 3, the PCL was divided into bins of five units and then combined, where needed, to ensure a minimum of 10 observations per bin to provide a stable measure. For Figure 4, this means that the three bins from 57 to 71 were combined. The plots are again fairly linear and show similar patterns for the points above and below the statistical cutoff for PTSD. The correlations of the PCL with Negative Intensity, the BDI, and the CES for all 533 participants are $.42, .63$, and .55 , respectively. For the 456 participants with PCL scores below 44, these correlations are reduced somewhat as might be expected from the restricted range of the PCL to $.32, .48$, and .46 , respectively. However, the correlation is not stronger in the 77 participants with PCL scores above 43 who might have PTSD. These correlations are .24, .39, and .32, respectively. Thus, as in the correlations and discussion for Figure 3, the results are again consistent with the disposition of Negative Intensity being a predisposing factor and the BDI and the CES varying continuously with PTSD symptom severity rather than having their higher levels being caused by PTSD.

\section{Comparisons of the Correlations in Studies 1 and 3}

In Study 1, participants were selected because of their extreme initial values on the PCL in a group-testing situation. This selection process produced a relatively uniform distribution during a retest on the PCL, which could artificially inflate correlations, but this did not appear to happen to a major extent. The correlation of the PCL and BDI in Study 1, as shown in Table 2, was .70, and it is .63 here. The correlation of the PCL and CES in Study 1, as shown in Table 2, was .56, and it is .53 here. In addition, the pattern of correlations among the individual PTSD criteria and symptoms were similar, with the A1 producing smaller correlations than the $\mathrm{A} 2$ and with the B symptoms having the numerically smallest correlation for the BDI and the D symptoms having the numerically smallest correlation for the CES. 


\section{Summary and Discussion of Study 3}

The AIM as a whole did not correlate highly with the PCL. However, the Negative Intensity scale of the AIM, which was found in several other studies, was also found here. It contains all of the items that correlate most highly with the PCL. Thus, our idea that the personality trait or disposition of having intense emotional states, especially for negative emotions, is a predisposing factor for the experiencing of PTSD symptoms is supported. Where comparisons were available, it appears that the distribution of PCL scores in Study 1 did not greatly distort our findings. In addition, the pattern of correlations of the BDI and CES with the A1, A2, B, C, and D components of PTSD was replicated, adding support to the conclusions drawn earlier.

\section{General Discussion}

\section{A Brief Summary}

The work reported here has been framed as a contrast between two views: the special and the basic mechanisms views. We therefore begin by reviewing the results in terms of this contrast before proposing a new theory that incorporates our findings. In order to provide the three-way set of comparisons needed to test existing theories, we obtained involuntary and voluntary memories of stressful and control events in participants who varied in PTSD symptom severity. All memories in participants with high PTSD symptom severity and memories for stressful events in all participants produced more emotional intensity, higher frequency of voluntary and involuntary retrieval, but not more narrative fragmentation. Moreover, there were minimal interactions among the three factors. The increase in emotional intensity with increasing PTSD symptoms and emotional distress of the event is consistent with both the special and basic mechanisms views. However, the increased availability of voluntary memories and the lack of increased fragmentation are inconsistent with the special mechanisms view. Involuntary memories were similar to voluntary memories except that they had more emotional intensity and less centrality to the life story. These differences were for all involuntary memories in all participants and are consistent with the basic mechanisms view in that they can be understood using what is known about retrieval in general. However, these differences are inconsistent with the special mechanisms view. In short, no special trauma mechanisms were needed to account for the results. Thus, we can formulate a theory of PTSD that is based on general principles of memory and personality and makes use of the current results.

\section{Where to Go Next: The Autobiographical Memory Theory of PTSD}

The work reported here is part of a larger project in which we have been applying what is known about the basic science of autobiographical memory to PTSD. In this effort, we produced four theoretical statements, or models, that are the foundation of what follows here. The basic-systems model of episodic memory (Rubin, 2006) surveyed what is known about the components needed to form and maintain an autobiographical memory at both the neural and the behavioral level. From this model, we could obtain and theoretically justify the set of questions asked using the AMQ as a comprehensive description of autobiographical memories. In this way, we could see what aspects of the memories changed or did not change over conditions and individuals. The episodic memory theory of involuntary autobiographical memory (Berntsen, in press) examined the theoretical history and empirical evidence on involuntary autobiographical memories including the evidence from diary studies of reports of involuntary memories as they occur. From this theory, we had support that involuntary memories do not differ greatly from voluntary memories in their contents, only in their retrieval processes, and that the differences that do exist can be seen as straightforward results of those retrieval processes. Also, this theory attempts to extend observations on everyday involuntary autobiographical memories to account for intrusive trauma memories.

Both the basic-systems model and the episodic memory theory of involuntary autobiographical memories are part of long-term experimental research programs that have provided theoretical integration of data on the nature of voluntary memory (e.g., Daselaar et al., 2008; Greenberg et al., 2005; Greenberg \& Rubin, 2003; Rubin, 1998, 2005; Rubin \& Greenberg, 1998, 2003; Rubin, Schrauf, \& Greenberg, 2003) and involuntary memory (Berntsen, 1996, 1998, 2001, in press; Berntsen \& Hall, 2004; Berntsen \& Rubin, 2002, 2008; Hall \& Berntsen, 2008). As part of these programs of research, the CES applied basic ideas about the availability of autobiographical memories to traumatic events (Berntsen \& Rubin, 2006c, 2007). On the basis of an immense amount of data and theory, it makes the claim that the more easily a memory of a highly stressful or traumatic event comes to mind, the worse PTSD symptoms will be. Although this claim may make intuitive sense, it is counter to the special mechanisms view that a lack of voluntary access to the trauma memory is associated with PTSD. Finally, the mnemonic model of PTSD (Rubin et al., in press) examined the assumptions underlying the diagnosis of PTSD in terms of what we know about the basic cognitive science of autobiographical memory and the empirical literature on PTSD. It challenges the idea that an $\mathrm{A} 1$ event and $\mathrm{A} 2$ emotion are necessary to produce the $\mathrm{B}, \mathrm{C}$, and D symptoms of PTSD and argues strongly that the memory of the event maintains the symptoms and so the standard changes that occur in all memories and especially emotional memories need to be considered.

What all these lines of research have in common is a challenge to most current theories of PTSD, a challenge that is based on solid empirical findings in cognitive, social, neuropsychological, and neuroimaging studies. They all converge on the idea that special mechanisms are not needed to account for PTSD. The surprisingly clear results obtained here finally allow us to formulate a theory about what is happening and to go beyond our arguments that special mechanisms are not needed. By way of introduction, we present a short overview of the autobiographical memory theory of PTSD (AMT) by examining the processes that it claims produce PTSD symptoms. Some people remember both positive and negative events as more emotionally intense than do other people, consistent with the concept of affect intensity developed by Larsen and Diener (1987). In Studies 1 and 2, we found that for people with higher PCL scores, the increase in intensity is mainly for negative events. In Study 3, we found that the Negative Intensity factor of the AIM correlates with PTSD symptom severity. Because 
emotional intensity enhances memory, for such people emotional events will become even more available than they are for other people. In particular, the memory of emotional events will be rehearsed more, come more often as involuntary memories, and become more central to their life story, causing further rehearsal. The rehearsal will maintain the memory and its emotional impact for longer periods. Neuroticism will act in a similar way to increase the availability of negative events. These findings are all within the normal range and have nothing to do with psychopathology. However, if a person with these tendencies experiences an extremely negative stressful or traumatic event (or a series of them), that person will have a negative memory of the event that is more available and better maintained and therefore will show more PTSD symptom severity for the event and will show it for longer. Thus, the same event will affect people differently, with both the event and the person to whom it occurs being important in predicting symptoms. Though we concentrated on the person here, the event is important and the AMT is consistent with the observation that a series of severe traumatic events could lead to PTSD symptoms in nearly everyone (Neuner et al., 2004).

Because involuntary memories of all kinds, including those of traumatic events, come out of the blue and are cued by thoughts or the environment in ways that are unexpected to the person instead of by a directed, voluntary search, they will benefit much less from mechanisms of emotion regulation. Therefore, involuntary memories of traumatic events will come with much more emotional reaction and mood change and be more noticeable and intrusive than are their voluntary counterparts, producing many of the reliving symptoms of PTSD. Conditioned emotional responses and other implicit memory effects to the stressful event will be evoked by voluntary and involuntary retrieval of the event. Avoidance symptoms will result from trying to avoid situations and thoughts that might cue the stressful memory because its increased intensity makes it more aversive. Whether other mechanisms are needed to provide for the full set of symptoms is an open question, but we would expect them to be general as opposed to special for trauma or PTSD, and we expect the increased availability of and emotional reaction to the autobiographical memory of the stressful event to remain as the key causes.

\section{Limitations}

This study has several limitations that could be overcome with additional research. Most of these limitations arise from the inability to offer a more rigorous test of the AMT. The first limitation is the need for a prospective study that measures individual difference variables including PTSD symptoms and autobiographical memory reports and ratings of samples of memories before a major stressful event occurs and that monitors the individual differences variables and the memory for the stressful and other events longitudinally. Although such a study would be difficult to complete, it would be the ideal way to test the AMT or any alternative model that views PTSD as a process caused by a particular individual interacting with a negative event.

A second major limitation is the lack of any measure of the severity of the stressful event beyond the retrospective report of the participants of the A1 criterion. In order to study the interaction of the event and the memory processes that record and maintain it, it would be helpful to have an objective measure of the seriousness of the event that was not filtered through the participant because all such reports already involve the effects of individual differences. A general scale of objective stress may be impossible to develop precisely because the filtering through individual perceptions is needed. However, for individuals in the same culture who (a) have military combat records, (b) have endured the same number of severe traumas (Neuner et al., 2004), (c) have emergency room records from similar traumas, (d) live the same distance from the epicenter of an earthquake, or (e) have experienced other similar situations, such a scale may be possible. The idea of a dose-response curve of severity often does not work (McNally, 2003a, 2003b), but with a reasonable scale in a fairly uniform population, it may be possible to study the person-environment interaction.

A third limitation was a strength for some purposes. Our participants were all young adults, of above average intelligence, with no psychopathology severe enough to prevent them from their competitive academic programs. It is extremely likely from demographic information and informal conversation that no participant had spent an extended time in a war zone, had a major physical disability from his or her most stressful event, had more than a few extremely stressful events, had PTSD symptoms for more than 10 years, was living in a homeless shelter, or had many of the other properties that might be common in other research samples. This study sample allowed us (a) to make plausible claims about predisposing conditions, (b) not to have to worry that differences in judgments of narrative coherence might be due to differences in intelligence or education (Gray \& Lombardo, 2001), and (c) not to have to worry about many of the other confounding comorbidity issues that arise in more diverse samples. However, the relatively homogeneous nature of the participants and fairly mild nature of the stressful events in our sample mean that other samples are needed. Along these lines, one might also see the lack of a formal diagnosis as a limitation. We do not see this as a main problem for our claims, given our desire to relax the $\mathrm{A}$ criterion in order to study it and the high concordance between the two continuous symptom severity scales we used and a formal clinical assessment once the A criterion is met (Blanchard et al., 1996; Davidson et al., 1997). However, it is a limitation that should be countered, and we have begun tests on more heterogeneous clinician-diagnosed samples to provide converging evidence.

\section{Conclusion}

Given the complexity of the design and number of dependent measures used, the results of our studies were extremely simple. Emotional intensity, whether measured as a personality attribute of the individual, as a characteristic of the overall memory style of the individual, or as a characteristic of individual voluntary or involuntary memories, was positively related to PTSD symptoms. These findings point directly to a novel view of the role of autobiographical memory in PTSD and challenge earlier work positing special mechanisms. 


\section{References}

American Psychiatric Association. (2000). Diagnostic and statistical manual of mental disorders (4th ed., text rev.). Washington, DC: American Psychiatric Association.

Asch, S. E., \& Ebenholtz, S. M. (1962). The principle of associative symmetry. Proceedings of the American Philosophical Society, 106, 135-163.

Beck, A. T., Steer, R. A., \& Brown, G. K. (1996). Manual for the Beck Depression Inventory - II. San Antonio, TX: Psychological Corporation.

Bernstein, E. M., \& Putnam, F. W. (1986). Development, reliability and validity of a dissociation scale. Journal of Nervous and Mental Disease, 174, 727-734.

Berntsen, D. (1996). Involuntary autobiographical memories. Applied Cognitive Psychology, 10, 435-454.

Berntsen, D. (1998). Voluntary and involuntary access to autobiographical memory. Memory, 6, 113-141.

Berntsen, D. (2001). Involuntary memories of emotional events. Do memories of traumas and extremely happy events differ? Applied Cognitive Psychology, 15, 135-158.

Berntsen, D. (2002). Tunnel memories for autobiographical events: Central details are remembered more frequently from shocking than from happy experiences. Memory \& Cognition, 30, 1010-1020.

Berntsen, D. (in press). Involuntary autobiographical memories. An introduction to the unbidden past. Cambridge University Press.

Berntsen, D., \& Hall, N. M. (2004). The episodic nature of involuntary autobiographical memories. Memory \& Cognition, 32, 789-803.

Berntsen, D., \& Rubin, D. C. (2002). Emotionally charged autobiographical memories across the lifespan: The recall of happy, sad, traumatic, and involuntary memories. Psychology and Aging, 17, 636-652.

Berntsen, D., \& Rubin, D. C. (2004). Cultural life scripts structure recall from autobiographical memory. Memory \& Cognition, 32, 427-442.

Berntsen, D., \& Rubin, D. C. (2006a). Emotion and vantage point in autobiographical memory. Cognition and Emotion, 20, 1193-1215.

Berntsen, D., \& Rubin, D. C. (2006b). Flashbulb memories and posttraumatic stress reactions across the life-span: Age-related effects of the German occupation of Denmark during WWII. Psychology and Aging, 21, 127-139.

Berntsen, D., \& Rubin, D. C. (2006c). The Centrality Of Event Scale: A measure of integrating a trauma into one's identity and its relation to post-traumatic stress disorder symptoms. Behaviour Research and Therapy, 44, 219-231.

Berntsen, D., \& Rubin, D. C. (2007). When a trauma becomes a key to identity: Enhanced integration of trauma memories predicts posttraumatic stress disorder symptoms. Applied Cognitive Psychology, 21, 417-431.

Berntsen, D., \& Rubin, D. C. (2008). The reappearance hypothesis revisited: Recurrent involuntary memories after traumatic events and in everyday life. Memory \& Cognition, 36, 449-460.

Berntsen, D., Willert, M., \& Rubin, D. C. (2003). Splintered memories or vivid landmarks? Qualities and organization of traumatic memories with and without PTSD. Applied Cognitive Psychology, 17, 675-693.

Blanchard, E. B., Jones-Alexander, J., Buckley, T. C., \& Foneris, C. A. (1996). Psychometric properties of the PTSD Checklist (PCL). Behaviour, Research and Therapy, 34, 669-673.

Brewin, C. R. (2007). Autobiographical memory for trauma: Update on four controversies. Memory, 15, 227-248.

Brewin, C. R., Dalgleish, T., \& Joseph, S. (1996). A dual representation theory of posttraumatic stress disorder. Psychological Review, 103, 670-686.

Brewin, C. R., \& Holmes, E. A. (2003). Psychological theories of posttraumatic stress disorder. Clinical Psychology Review, 23, 339-376.

Bryant, F. B., Yarnold, P. R., \& Grimm, L. G. (1996). Toward a measurement model of the affect intensity measure: A three-factor structure. Journal of Research in Personality, 30, 223-247.
Carlson, E. B., \& Putnam, F. W. (1993). An update on the Dissociative Experiences Scale. Dissociation, 6, 16-27.

Christianson, S.-Å. (1992). Emotional stress and eyewitness memory: A critical review. Psychological Bulletin, 112, 284-309.

Conway, M. A. (1997). (Ed.). Recovered memories and false memories. Oxford, England: Oxford University Press.

Conway, M. A. (2005). Memory and the self. Journal of Memory and Language, 53, 594-628.

Conway, M. A., \& Pleydell-Pearce, C. W. (2000). The construction of autobiographical memories in the self-memory system. Psychological Review, 107, 261-288.

Costa, P. T., Jr., \& McCrae, R. R. (1992). Revised NEO Personality Inventory (NEO-PIR) and the NEO Five-Factor Inventory (NEO-FFI) professional manual. Odessa, FL: Psychological Assessment Resources.

Crovitz, H. F., \& Schiffman, H. (1974). Frequency of episodic memories as a function of their age. Bulletin of the Psychonomic Society, 4, $517-518$.

Dalgleish, T. (2004). Cognitive approaches to posttraumatic stress disorder: The evolution of multirepresentational theorizing. Psychological Bulletin, 130, 228-260.

Daselaar, S. M., Rice, H. J., Greenberg, D. L., Cabeza, R. LaBar, K. S., \& Rubin, D. C. (2008). The spatiotemporal dynamics of autobiographical memory: Neural correlates of recall, emotional intensity, and reliving. Cerebral Cortex, 18, 217-229.

Davidson, J. R. T., Book, S. W., Colket, J. T., Tupler, L. A., Roth, S., David, D., et al. (1997). Assessment of a new self-rating scale for post-traumatic stress disorder: The Davidson Trauma Scale. Psychological Medicine, 27, 153-160.

Ehlers, A., \& Clark, D. M. (2000). A cognitive model of posttraumatic stress disorder. Behavior Research and Therapy, 38, 319-345.

Erdoğan, A., Baran, B., Alvar, B., Taş, A. C., \& Tekcan, A. İ. (2008). On the persistence of positive events in life scripts. Applied Cognitive Psychology, 22, 95-111.

Ericsson, K. A., \& Simon, H. A. (1993). Protocol analysis: Verbal reports as data (Rev. ed.). Cambridge, MA: MIT (Bradford Books).

Frankel, F. H. (1994). The concept of flashback in historical perspective. The International Journal of Clinical and Experimental Hypnosis, 42, 321-336.

Fredrickson, B. L. (2001). The role of positive emotions in positive psychology: The broaden-and-build theory of positive emotions. American Psychologist, 56, 218-226.

Fredrickson, B. L., \& Branigan, C. (2005). Positive emotions broaden the scope of attention and thought-action repertoires. Cognition and Emotion, 19, 313-332.

Freyd, J. J. (1994). Betrayal-trauma: Traumatic amnesia as an adaptive response to childhood abuse. Ethics \& Behaviour, 4, 307-329.

Galton, F. (1879). Psychometric experiments. Brain, 2, 149-162.

Geraerts, E., Kozaric-Kovacic, D., Merckelbach, H., Peraica, T., Jelicic, M., \& Candel, I. (2007). Traumatic memories in war veterans: Not so special after all. Consciousness and Cognition, 16, 170-177.

Gray, M. J., \& Lombardo, T. W. (2001). Complexity of trauma narratives as an index of fragmented memory in PTSD: A critical analysis. Applied Cognitive Psychology, 15, S171-S186.

Greenberg, D. L., Eacott, M. J., Brechin, D., \& Rubin, D. C. (2005). Visual memory loss and autobiographical amnesia: A case study. Neuropsychologia, 43, 1493-1502.

Greenberg, D. L., \& Rubin, D. C. (2003). The neuropsychology of autobiographical memory. Cortex, 39, 687-728.

Gross, J. J. (2001). Emotion regulation in adulthood: Timing is everything. Current Directions in Psychological Science, 10, 214-219.

Hall, N. M., \& Berntsen, D. (2008). The effect of emotional stress on involuntary and voluntary conscious memories. Memory. 16, 48-57.

Halligan, S. L., Clark, D. M., \& Ehlers, A. (2002). Cognitive processing, memory, and the development of PTSD symptoms: Two experimental 
analogue studies. Journal of Behavior Therapy and Experimental Psychiatry, 33, 73-89.

Hellaway, S. J., \& Brewin, C. R. (2002). A comparison of flashbacks and ordinary autobiographical memories of trauma: Cognitive resources and behavioral observations. Behavior Research and Therapy, 42, 1-12.

Horowitz, M. J. (1986). Stress response syndromes (2nd ed.). Northvale, NJ: Jason Aronson.

Janoff-Bulman, R. (1988). Assumptive worlds and the stress of traumatic events: Applications of the schema construct. Social Cognition, 7, 113-136.

Kihlstrom, J. F. (1997). Suffering from reminiscences: Exhumed memory, implicit memory and the return of the repressed. In M. A. Conway (Ed.), Recovered memories and false memories (pp. 100-117). Oxford, England: Oxford University Press.

Kihlstrom, J. F. (2006). Trauma and memory revisited. In B. Uttl, N. Ohta, \& A. L. Siegenthaler (Eds.), Memory and emotion. Interdisciplinary perspectives (pp. 259-291). Malden, MA: Blackwell.

Larsen, R. J. (in press). Affect intensity: Individual differences in emotional response. In M. R. Leary \& R. H. Hoyle (Eds.), Handbook of individual differences in social behavior. New York: Guilford.

Larsen, R. J., \& Diener, E. (1987). Affect intensity as an individual difference characteristic: A review. Journal of Research in Personality, 21, 1-39.

Larsen, R. J., Diener, E., \& Emmons, R. A. (1986). Affect intensity and reactions to daily life events. Journal of Personality and Social Psychology, 51, 803-814.

Loftus, E. F. (1993). The reality of repressed memories. American Psychologist, 48, 518-537.

Lynch, T. R., Robins, C. J., Morse, J. Q., \& Krause, E. D. (2001). A mediational model relating affect intensity, emotion inhibition, and psychological distress. Behavior Therapy, 32, 519-536.

McGaugh, J. L. (2003). Memory and emotion. The making of lasting memories. New York: Columbia University Press.

McNally, R. J. (2003a). Progress and controversy in the study of posttraumatic stress disorder. Annual Review of Psychology, 54, 229-252.

McNally, R. J. (2003b). Remembering trauma. Cambridge, MA: Harvard University Press.

McNally, R. J. (2007). Dispelling confusion about traumatic dissociative amnesia. Mayo Clinic Proceedings, 82, 1083-1087.

Metcalfe, J., \& Jacobs, W. J. (1998). Emotional memory: The effects of stress on "cool" and "hot" memory systems. In D. L. Medin (Ed.), The psychology of learning and motivation: Advances in research and theory (Vol. 38, pp. 187-222). San Diego, CA: Academic Press.

Nadel, L., \& Jacobs, W. J. (1998). Trauma memory is special. Current Directions in Psychological Science, 7, 154-157.

Neuner, F., Schauer, M., Karunakara, U., Klaschik, C., Robert, C., \& Elbert, T. (2004). Psychological trauma and evidence for enhanced vulnerability for posttraumatic stress disorder through previous trauma among West Nile refugees. BMC Psychiatry, 4, 34. doi: 10.1186/1471244x-4-34

Peace, K. A., Porter, S., \& ten Brinke, L. (2008). Are memories for sexually traumatic events "special"? A within-subjects investigation of trauma and memory in a clinical sample. Memory, 16, 10-21.

Porter, S., \& Birt, A. R. (2001). Is traumatic memory special? A comparison of traumatic memory characteristics with memory for other emotional life experiences. Applied Cognitive Psychology, 15, 1-17.

Read, D. J., \& Winograd, E. (1998). Introduction. Applied Cognitive Psychology, 12, S1-S4.

Rubin, D. C. (1983). Associative asymmetry, availability, and retrieval. Memory and Cognition, 11, 83-92.

Rubin, D. C. (1998). Beginnings of a theory of autobiographical remembering. In C. P. Thompson, D. J. Herrmann, D. Bruce, J. D. Reed, D. G. Payne, \& M. P. Toglia (Eds.), Autobiographical memory:
Theoretical and applied perspectives (pp. 47-67). Mahwah, NJ: Erlbaum.

Rubin, D. C. (2005). A basic-systems approach to autobiographical memory. Current Directions in Psychological Science, 14, 79-83.

Rubin, D. C. (2006). The basic-systems model of episodic memory. Perspectives on Psychological Science, 1, 277-311.

Rubin, D. C., \& Berntsen, D. (2003). Life scripts help to maintain autobiographical memories of highly positive, but not highly negative, events. Memory \& Cognition, 31, 1-14

Rubin, D. C., Berntsen, D., \& Hutson, M. (2007). The normative and the personal life: Individual differences in life scripts and life stories among U.S.A. and Danish Undergraduates. Unpublished manuscript.

Rubin, D. C., Berntsen, D., \& Bohni, M. K. (in press). A memory based model of posttraumatic stress disorder: Evaluating basic assumptions underlying the PTSD diagnosis. Psychological Review.

Rubin, D. C., Feldman, M. E., \& Beckham, J. C. (2003). Reliving, emotions, and fragmentation in the autobiographical memories of veterans diagnosed with PTSD. Applied Cognitive Psychology, 18, 17-35.

Rubin, D. C., \& Greenberg, D. L. (1998). Visual memory deficit amnesia: A distinct amnesic presentation and etiology. Proceedings of the National Academy of Sciences, USA, 95, 5413-5416.

Rubin, D. C., \& Greenberg, D. L. (2003). The role of narrative in recollection: A view from cognitive and neuropsychology. In G. Fireman, T. McVay, \& O. Flanagan (Eds.), Narrative and consciousness: Literature, psychology, and the brain (pp. 53-85). New York: Oxford University Press.

Rubin, D. C., Schrauf, R. W., \& Greenberg, D. L. (2003). Belief and recollection of autobiographical memories. Memory \& Cognition 31, 887-901.

Rubin, D. C., Schrauf, R. W., \& Greenberg, D. L. (2004). Stability in autobiographical memories. Memory, 12, 715-721.

Rubin, D. C., Schrauf, R. W., Gulgoz, S., \& Naka, M. (2007). On the cross-cultural variability of component processes in autobiographical remembering: Japan, Turkey, and the U.S.A. Memory, 15, 536-547.

Rubin, D. C., \& Siegler. I. C. (2004). Facets of personality and the phenomenology of autobiographical memory. Applied Cognitive Psychology, 18, 913-930.

Sheen, M., Kemp, S., \& Rubin, D. C. (2001). Twins dispute memory ownership: A new false memory phenomenon. Memory \& Cognition, $29,779-788$.

Simonsson-Sarnecki, M., Lundh, L., \& Törestad, B. (2000). Factor structure and validity of the affect intensity measure in a Swedish sample. Personality and Individual Differences, 29, 337-350.

Talarico, J. M., Berntsen, D, \& Rubin, D. C. (in press). Positive emotions enhance recall of peripheral details. Cognition \& Emotion.

Talarico, J. M., LaBar, K. S., \& Rubin, D. C. (2004). Emotional intensity predicts autobiographical memory experience. Memory \& Cognition, 32, $1118-1132$

Talarico, J. M., \& Rubin, D. C. (2003). Confidence, not consistency, characterizes flashbulb memories. Psychological Science, 14, 455-461.

Talarico, J. M., \& Rubin, D. C. (2007). Flashbulb memories are special after all; in phenomology, not accuracy. Applied Cognitive Psychology, $21,557-558$

Thorndike, E. L. (1932). The fundamentals of learning. New York: Bureau of Publications, Teachers College.

Tulving, E. (1983). Elements of episodic memory. New York: Oxford University Press.

Tulving, E., \& Pearlstone, Z. (1966). Availability versus accessibility of information in memory for words. Journal of Verbal Learning and Verbal Behavior, 5, 381-391.

Tversky, A., \& Kahneman, D. (1973). Availability: A heuristic for judging frequency and probability. Cognitive Psychology, 5, 207-232.

Van der Kolk, B. A., \& Fisler, R. (1995). Dissociation and the fragmentary nature of traumatic memories: Overview and exploratory study. Journal of Traumatic Stress, 8, 505-525. 
Watson, D., \& Clark, L. A. (1984). Negative affectivity: The disposition to experience aversive emotional states. Psychological Bulletin, 96, 465-490.

Weathers, F. W., Litz, B. T., Huska, J. A., \& Keane, T. M. (1994). The PTSD Checklist (PCL). (Available from the National Center for PTSD, VA Boston Healthcare System, 150 South Huntington Avenue, Boston, MA 02130).

Wegner, D. M., \& Zanakos, S. (1994). Chronic thought suppression. Journal of Personality, 62, 615-640.

Weinfurt, K. P., Bryant, F. B., \& Yarnold, P. R. (1994). The factor structure of the affect intensity measure: In search of a measurement model. Journal of Research in Personality, 28, 314-331.

Wenzel, A., Pinna, K., \& Rubin, D. C. (2004). Autobiographical memories of anxiety-related experiences. Behaviour Research and Therapy, 42, 329-341.

Williams, D. G. (1989). Neuroticism and extraversion in different factors of the affect intensity measure. Personality and Individual Differences, 10, 1095-1100.

Williams, J. M. G. (1996). Depression and the specificity of autobiographical memory. In D. C. Rubin (Ed.), Remembering our past: Studies in autobiographical memory (pp. 244-267). Cambridge, England: Cambridge University Press.

Zoellner, L. A., \& Bittenger, J. N. (2004). On the uniqueness of trauma memories in PTSD. In G. M. Rosen (Ed.), Posttraumatic stress disorder: Issues and controversies. (pp. 147-186). Chichester, England: Wiley.

Received April 1, 2008

Revision received June 3, 2008

Accepted June 4, 2008

\section{New Editors Appointed, 2010-2015}

The Publications and Communications Board of the American Psychological Association announces the appointment of 4 new editors for 6-year terms beginning in 2010. As of January 1 , 2009, manuscripts should be directed as follows:

- Psychological Assessment (http://www.apa.org/journals/pas), Cecil R. Reynolds, PhD, Department of Educational Psychology, Texas A\&M University, 704 Harrington Education Center, College Station, TX 77843.

- Journal of Family Psychology (http://www.apa.org/journals/fam), Nadine Kaslow, PhD, Department of Psychiatry and Behavioral Sciences, Grady Health System, 80 Jesse Hill Jr. Drive, SE, Atlanta, GA 30303.

- Journal of Experimental Psychology: Animal Behavior Processes (http://www.apa.org/ journals/xan), Anthony Dickinson, PhD, Department of Experimental Psychology, University of Cambridge, Downing Street, Cambridge CB2 3EB, United Kingdom

- Journal of Personality and Social Psychology: Personality Processes and Individual Differences (http://www.apa.org/journals/psp), Laura A. King, PhD, Department of Psychological Sciences, University of Missouri, McAlester Hall, Columbia, MO 65211.

Electronic manuscript submission: As of January 1, 2009, manuscripts should be submitted electronically via the journal's Manuscript Submission Portal (see the website listed above with each journal title).

Manuscript submission patterns make the precise date of completion of the 2009 volumes uncertain. Current editors, Milton E. Strauss, PhD, Anne E. Kazak, PhD, Nicholas Mackintosh, $\mathrm{PhD}$, and Charles $\mathrm{S}$. Carver, $\mathrm{PhD}$, will receive and consider manuscripts through December 31, 2008. Should 2009 volumes be completed before that date, manuscripts will be redirected to the new editors for consideration in 2010 volumes. 